\title{
Discovery of potential anti-SARS-CoV-2 drugs based on large-scale screening in vitro and effect evaluation in vivo
}

\author{
Haoran Peng ${ }^{1 \dagger}$, Cuiling Ding ${ }^{1 \dagger}$, Liangliang Jiang ${ }_{1}^{1 \dagger}$, Wanda Tang ${ }^{1}$, Yan Liu ${ }^{1}$, Lanjuan Zhao ${ }^{1}$, \\ Zhigang $\mathrm{Yi}^{2}$, Hao Ren ${ }^{1}$, Chong $\mathrm{Li}^{3}$, Yanhua $\mathrm{He}^{1}, \mathrm{Xu}$ Zheng ${ }^{1}$, Hailin Tang ${ }^{1}$, Zhihui Chen ${ }^{4 *}$, \\ Zhongtian $\mathrm{Qi}^{1^{*}} \&$ Ping Zhao ${ }^{1 *}$ \\ ${ }^{1}$ Department of Microbiology, Second Military Medical University, Shanghai Key Laboratory of Medical Biodefense, Shanghai 200433, China; \\ ${ }^{2}$ Key Laboratory of Medical Molecular Virology (MOE/NHC/CAMS), School of Basic Medical Sciences, Shanghai Medical College, Fudan \\ University, Shanghai 200032, China; \\ ${ }^{3}$ Cancer Institute, Fudan University Shanghai Cancer Center, Department of Oncology, Shanghai Medical College, Fudan University, \\ Shanghai 200032, China; \\ ${ }^{4}$ Department of Infectious Disease, Changhai Hospital, Shanghai 200433, China
}

Received September 9, 2021; accepted November 17, 2021; published online December 24, 2021

\begin{abstract}
The coronavirus disease 2019 (COVID-19) pandemic caused by severe acute respiratory syndrome coronavirus 2 (SARS$\mathrm{CoV}-2$ ) is a global crisis. Clinical candidates with high efficacy, ready availability, and that do not develop resistance are in urgent need. Despite that screening to repurpose clinically approved drugs has provided a variety of hits shown to be effective against SARS-CoV-2 infection in cell culture, there are few confirmed antiviral candidates in vivo. In this study, 94 compounds showing high antiviral activity against SARS-CoV-2 in Vero E6 cells were identified from 2,580 FDA-approved small-molecule drugs. Among them, 24 compounds with low cytotoxicity were selected, and of these, 17 compounds also effectively suppressed SARS-CoV-2 infection in HeLa cells transduced with human ACE2. Six compounds disturb multiple processes of the SARS$\mathrm{CoV}-2$ life cycle. Their prophylactic efficacies were determined in vivo using Syrian hamsters challenged with SARS-CoV-2 infection. Seven compounds reduced weight loss and promoted weight regain of hamsters infected not only with the original strain but also the D614G variant. Except for cisatracurium, six compounds reduced hamster pulmonary viral load, and $I L-6$ and $T N F-\alpha$ mRNA when assayed at $4 \mathrm{~d}$ postinfection. In particular, sertraline, salinomycin, and gilteritinib showed similar protective effects as remdesivir in vivo and did not induce antiviral drug resistance after 10 serial passages of SARS-CoV-2 in vitro, suggesting promising application for COVID-19 treatment.
\end{abstract}

SARS-CoV-2, drug repurposing, drug screening, hamster model, D614G variant, drug resistance

Citation: Peng, H., Ding, C., Jiang, L., Tang, W., Liu, Y., Zhao, L., Yi, Z., Ren, H., Li, C., He, Y., et al. (2022). Discovery of potential anti-SARS-CoV-2 drugs based on large-scale screening in vitro and effect evaluation in vivo. Sci China Life Sci 65, 1181-1197. https://doi.org/10.1007/s11427-021-2031-7

\section{INTRODUCTION}

Coronavirus disease 2019 (COVID-19) outbreak caused by severe acute respiratory syndrome coronavirus 2 (SARS-

$\uparrow$ Contributed equally to this work

*Corresponding authors (Zhihui Chen, email: hchzhi@126.com; Zhongtian Qi, email:

qizt@smmu.edu.cn; Ping Zhao, email: pnzhao@163.com)
CoV-2) continues to endanger human health and hamper global social and economic development. Various types of vaccines have been available and are being quickly disseminated worldwide. However, the current vaccines provide only limited protection against COVID-19 infection, although they can reduce the severeness of the illness. To make matters worse, more contagious and potentially pathogenic variants of SARS-CoV-2 are continually emerging 
and spread quickly around the world, so the global pandemic situation is far from under control. COVID-19 therapy is in urgent need of effective antiviral drugs. Remdesivir was authorized by the US Food and Drug Administration (FDA) for emergency use to treat COVID-19, which is the first and only drug officially authorized for this emerging viral disease so far. Recently, molnupiravir was reported to reduce the risk of hospital admission or death by $50 \%$ in patients of COVID-19 at risk (Mahase, 2021). However, molnupiravir inhibits viral propagation through lethal mutagenesis by introducing errors in the viral genome, and is also a mutagen to mammalian cells, the safety of which is particularly concerned (Zhou et al., 2021). Moreover, the constant emergence of SARS-CoV-2 variants of concern and the occurrence of SARS-CoV-2 chronic infections highlight the requirement for drugs with high resistance barriers.

To develop a novel antiviral drug, repurposing of clinically approved drugs for application in the treatment of an emerging viral infection has widely been used in recent years. This strategy is promising for rapidly identifying effective, safe, and readily available clinical candidates for COVID-19 treatment (Dittmar et al., 2021; Gao et al., 2020a; Han et al., 2021; Pandey et al., 2020; Patten et al., 2021; Riva et al., 2020). However, most repurposing investigations have only been performed to screen virus cell culture systems, and there are very few evaluations of efficacy against SARS$\mathrm{CoV}-2$ in vivo. Since large numbers of critical care patients are in urgent need of effective treatment, a number of repurposed drugs have entered clinical trials without animal testing (Li et al., 2021). Nevertheless, most drugs did not exhibit the desired therapeutic effects (Rakedzon et al., 2021). Thus, it is especially essential to evaluate the antiviral efficacy of clinical candidates for SARS-CoV-2 infection in animals.

Here, we carried out a high-throughput repurposing screening from an FDA-approved drug library containing 2,580 small-molecule compounds to identify candidates for the treatment of COVID-19. We identified 94 hits that inhibited SARS-CoV-2 infection in Vero E6 cells, among which 24 hits showed potent antiviral activity in a doseresponse dependent manner. Validation studies further confirmed that 17 of 24 selected compounds potently inhibited SARS-CoV-2 in a human cervical carcinoma cell line transduced with human ACE2 (HeLa-ACE2). Furthermore, the effects of the 17 compounds together with remdesivir in vivo were evaluated in a hamster SARS-CoV-2 infection model. The results showed that gilteritinib, salinomycin sodium salt, and sertraline $\mathrm{HCl}$ showed dramatic inhibitory activity against both the original SARS-CoV-2 strain and the D614G variant in vivo. None of the three candidates induced antiviral drug resistance after serial passages of SARSCoV-2 in vitro.

\section{RESULTS}

\section{Screening compounds with anti-SARS-CoV-2 activity from an FDA-approved drug library}

A high-throughput screening assay was performed to screen candidates for potential use in COVID-19 treatment from FDA-approved small-molecule drugs. Vero E6 cells and a SARS-CoV-2 strain isolated in March 2020 in Shanghai (GenBank accession No. MT622319) were used for this purpose. Figure 1A shows the procedure of the screening assay. Cells were seeded in 96-well plates. Then, $12 \mathrm{~h}$ later, a single dilution of each compound at a $5-\mu \mathrm{mol} \mathrm{L}^{-1}$ final concentration was added to the cells, which were then incubated with SARS-CoV-2 with an MOI of 0.1. At $24 \mathrm{~h}$ postvirus challenge, the infection of SARS-CoV-2 was measured by immunofluorescence of the expression of the SARS-CoV-2 nucleocapsid (N) protein. The screening assay was validated with remdesivir and hydrochloroquine, which inhibited SARS-CoV-2 infection in vitro (Wang et al., 2020) (Figure 1B).

A total of 2,580 FDA-approved small-molecule drugs were screened for anti-SARS-CoV-2 activity. Among these, 94 compounds showed potent antiviral activity against SARS-CoV-2, which could inhibit the infection of SARSCoV-2 in more than $90 \%$ of Vero E6 cells at a final concentration of $5 \mu \mathrm{mol} \mathrm{L}^{-1}$ (Table S1 in Supporting Information), including hydroxychloroquine. We first identified four compounds that showed antiviral activity against SARSCoV-2: perifosine, CB-5083, sodium phytate, and pimavanserin. To investigate their possible antiviral mechanisms, the enrichment of known targets of these 94 drugs was analyzed and classified. A total of 14 target classes were identified, among which the six main classes were receptor tyrosine kinase, hormone receptors (5-HT receptor, dopamine receptor, adrenergic receptor, and estrogen receptor), histamine $\mathrm{H} 1$ receptor, dihydrofolate reductase, Toll-like receptors, and sphingosine 1-phosphate (Figure 2A and B; Table S1 in Supporting Information). Meanwhile, we examined the pathways of the 94 compounds using the free online meta-analysis tool Metascape (Zhou et al., 2019). The top three pathways were cancer-related pathways, peptidyltyrosine phosphorylation, and ERK1 and ERK2 cascade (Figure 2C).

\section{Dose-response analysis}

The 94 compounds were subjected to determination of their $50 \%$ effective concentrations $\left(\mathrm{CC}_{50}\right)$ and $50 \%$ effective concentrations $\left(\mathrm{EC}_{50}\right)$ against SARS-CoV-2 and cytotoxicity in Vero E6 cells. The working concentration of the drugs was started at $20 \mu \mathrm{mol} \mathrm{L}{ }^{-1}$ and diluted serially eight times 2-fold $\left(20-0.15625 \mu \mathrm{mol} \mathrm{L}{ }^{-1}\right)$. Twenty-four compounds displaying low cytotoxicity with $\mathrm{CC}_{50}>20 \mu \mathrm{mol} \mathrm{L}^{-1}$ were selected for 
A


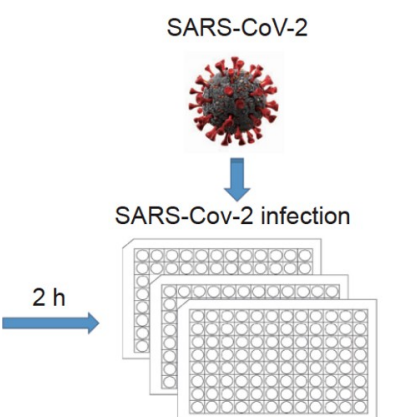

$24 \mathrm{~h}$



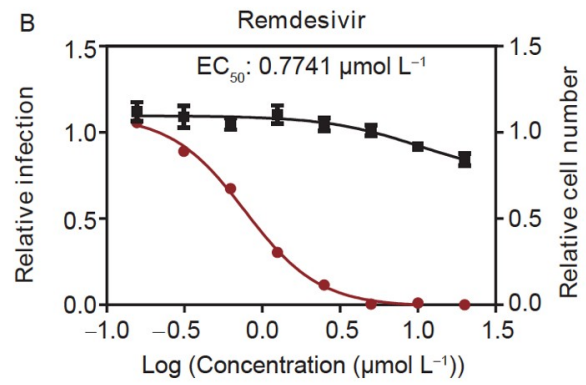

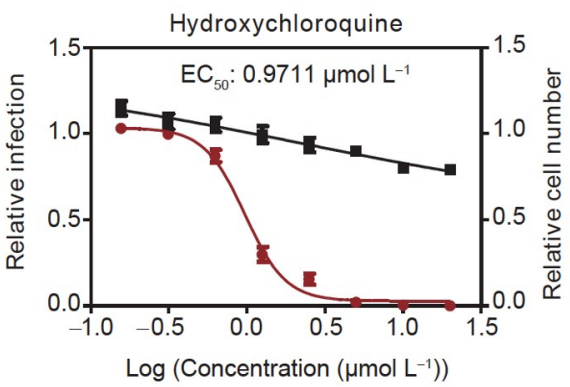

Figure 1 High-throughput screening for anti-SARS-CoV-2 compounds. A, A schematic of the screening strategy used for the repurposing analysis of FDAapproved small-molecule drugs against SARS-CoV-2 in Vero E6 cells. In total, $1 \times 10^{4}$ Vero E6 cells were seeded in 96 -well plates. Then, $12 \mathrm{~h}$ later, a single dilution of each compound at a $5-\mu \mathrm{mol} \mathrm{L}^{-1}$ final concentration was added to the cells and then incubated with SARS-CoV-2 with an MOI of 0.1 . The rate of SARS-CoV-2 infection was detected by immunofluorescence using an antibody against the nucleoprotein (NP) of SARS-CoV-2 at $24 \mathrm{~h}$ postinfection. B, Remdesivir and hydrochloroquine inhibited the infection of SARS-CoV-2 in a concentration-dependent manner. Vero E6 cells were pretreated for $2 \mathrm{~h}$ with eight 2-fold serial dilutions $\left(20-0.15625 \mu \mathrm{mol} \mathrm{L}^{-1}\right)$ of remdesivir and hydrochloroquine and then infected with SARS-CoV-2 at an MOI of 0.1 . Then, $24 \mathrm{~h}$ postinfection, cells were fixed, and then SARS-CoV-2 NP and cell nuclei were visualized by immunofluorescence imaging. Dose-response curves of remdesivir and hydrochloroquine show the infectivity (red), cell number (black), and cellular $\mathrm{EC}_{50}$ values. Data are normalized to the average of DMSOtreated wells and represent the mean \pm SEM for $n=3$ independent experiments.

further antiviral evaluation. Although highly dependent on the pharmacokinetic properties of a compound, it is generally expected that the therapeutic dose range should be a cellular $\mathrm{EC}_{50}$ value below $1 \mu \mathrm{mol} \mathrm{L}^{-1}$ (Riva et al., 2020). Among these 24 hits, the $\mathrm{EC}_{50}$ of five compounds were below $1 \mu \mathrm{mol} \mathrm{L}^{-1}$ (Figure 3). In particular, the $\mathrm{EC}_{50}$ of $\mathrm{CB}-5083$, cepharanthine, dronedarone, lomitapide mesylate, and ouabain were $0.5758,0.2583,0.8012, \quad 0.9082$, and $0.2599 \mu \mathrm{mol} \mathrm{L}^{-1}$, respectively. To further evaluate the antiviral effect of these 24 drugs, we used HeLa-ACE2 cells, which support SARS-CoV-2 replication, in a validation study. Dose-response analysis showed that 17 out of the 24 selected compounds inhibited SARS-CoV-2 infection in this cell line (Figure 4), and the remaining 7 compounds did not show an anti-SARS-CoV-2 effect at the concentration range of $20-0.15625 \mu \mathrm{mol} \mathrm{L}^{-1}$ (data not shown).

\section{Effects on the SARS-CoV-2 life cycle}

A time-of-drug addition assay was performed to determine the stage of the viral life cycle at which the 17 compounds are active. The viral infection of Vero E6 cells was assayed following hits administrated on $-2,0,2$, and $5 \mathrm{~h}$ after viral challenge (Figure 5A). The results indicated that gilteritinib, lomitapide mesylate, pimozide, prochlorperazine dimaleate salt, quinacrine $2 \mathrm{HCl}$, and sertraline $\mathrm{HCl}$ are likely to inhibit SARS-CoV-2 infection at the stage of postvirus cell entry and/or at cell entry (Figure 5A). The remaining 11 of 17 compounds inhibited SARS-CoV-2 replication only when added to cells at $-2 \mathrm{~h}$ (data not shown), which might impede the entry of SARS-CoV-2. To further confirm drugs that inhibit the SARS-CoV-2 spike glycoprotein (S)-mediated cell entry, we evaluated the effect of these 17 compounds on S-mediated entry using SARSCoV-2 pseudoparticles. Quinacrine $2 \mathrm{HCl}$, gilteritinib, and prochlorperazine dimaleate salt potently blocked the entry of SARS-CoV-2 pseudoparticles. Thioridazine $\mathrm{HCl}$ and sertraline $\mathrm{HCl}$ moderately suppressed pseudoparticle cell entry (Figure 5B). Unexpectedly, the 11 compounds that inhibited SARS-CoV-2 infection only when cells were pretreated with corresponding molecules showed no significant antiviral effect to SARS-CoV-2 pseudoparticles. Therefore, gilteritinib, lomitapide mesylate, pimozide, prochlorperazine dimaleate salt, quinacrine $2 \mathrm{HCl}$, and sertraline $\mathrm{HCl}$ play important roles in multiple stages of the virus life cycle. 

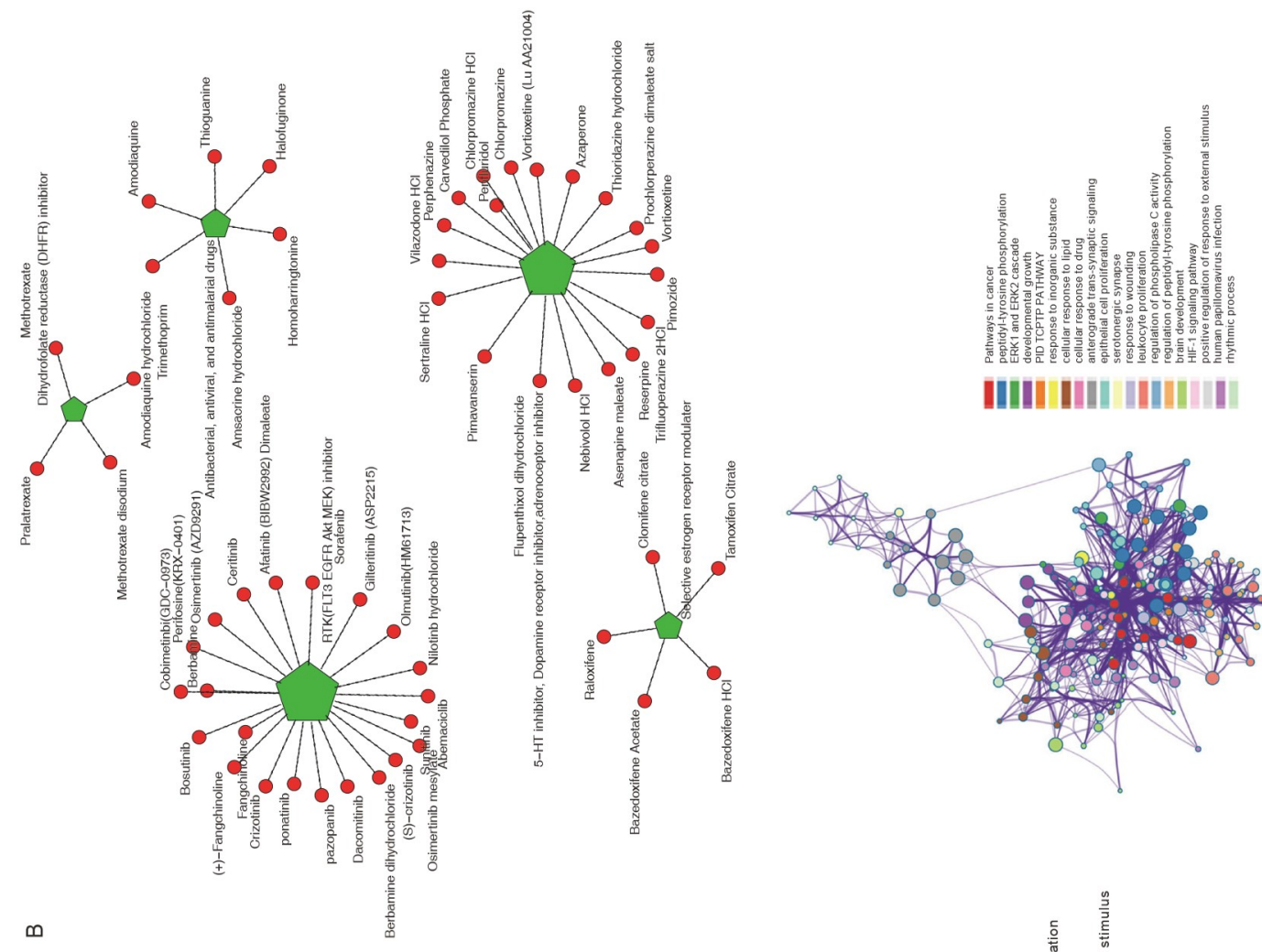

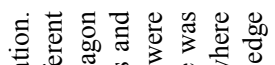

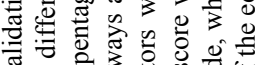



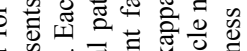
च 至

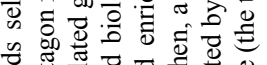
棓

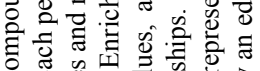

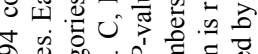

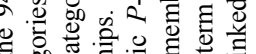

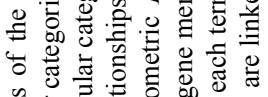

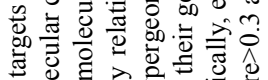
声记

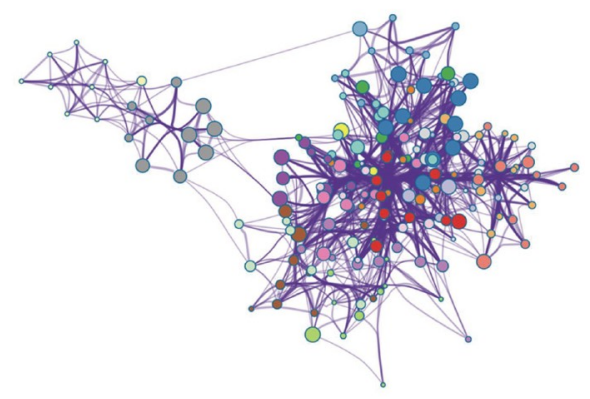

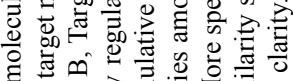

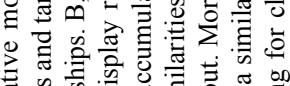

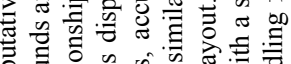

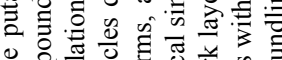

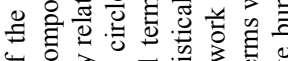

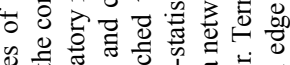
记



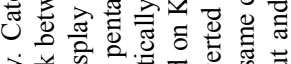



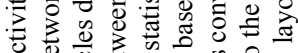

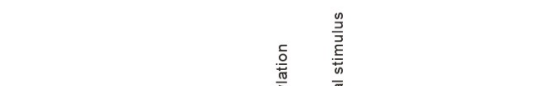
ง

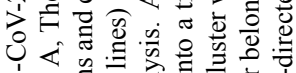

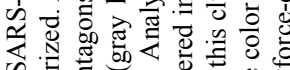

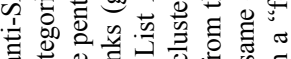
ฮ

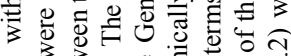
v 0 \%

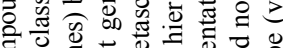

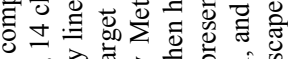

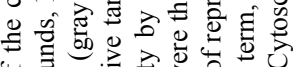
पे

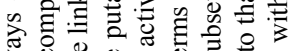

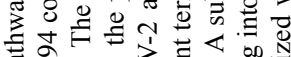

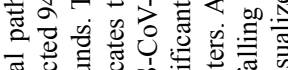

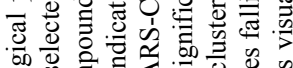

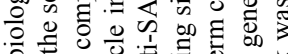

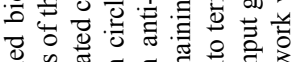

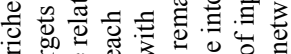

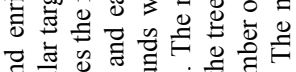

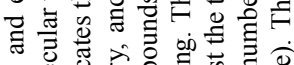

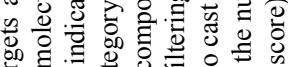

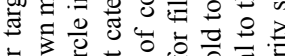

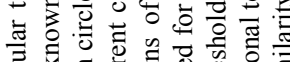

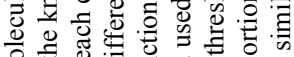

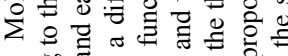

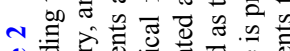

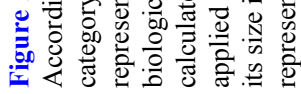




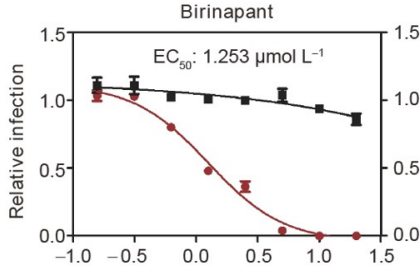

$\log \left(\right.$ Concentration $\left.\left(\mu \mathrm{mol} \mathrm{L}^{-1}\right)\right)$

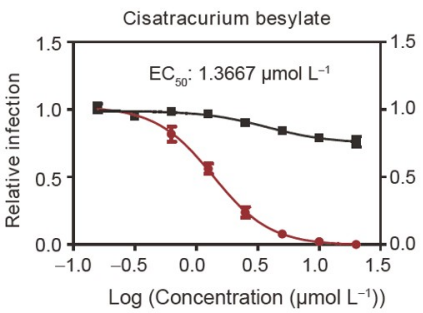

Log (Concentration $\left(\mu \mathrm{mol} \mathrm{L}^{-1}\right)$ )
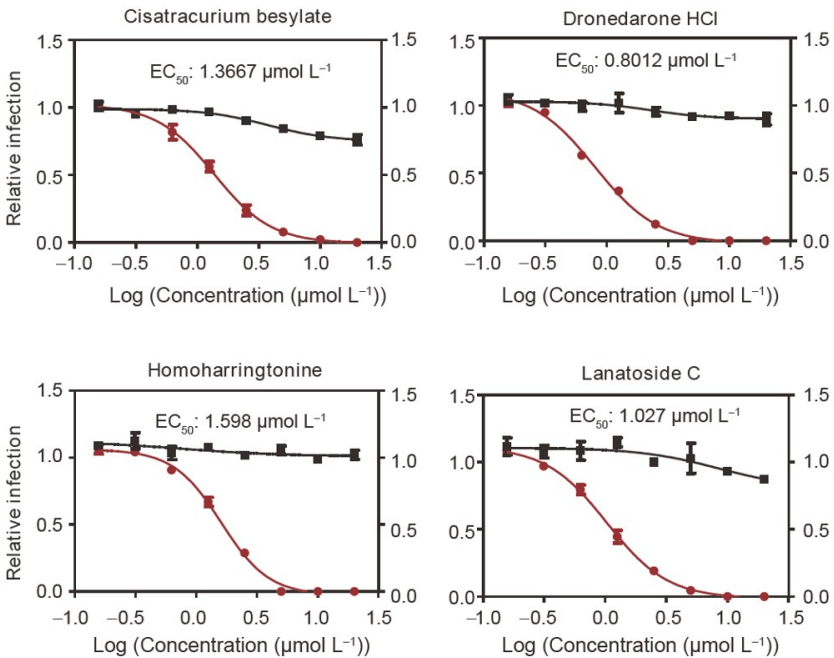

Log (Concentration ( $\left.\mu \mathrm{mol} \mathrm{L}^{-1}\right)$ )

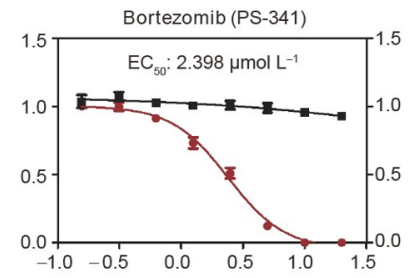

Log (Concentration $\left.\left(\mu \mathrm{mol} \mathrm{L}^{-1}\right)\right)$

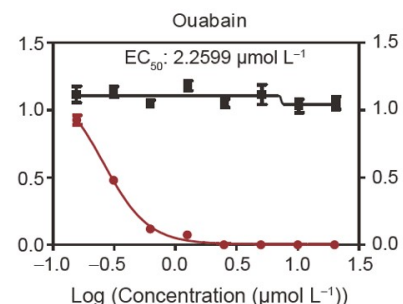

Log (Concentration $\left(\mu \mathrm{mol} \mathrm{L} \mathrm{L}^{-1}\right)$ )

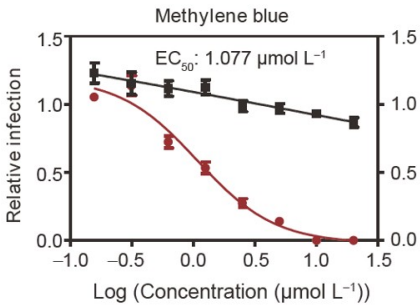

Log (Concentration $\left(\mu \mathrm{mol} \mathrm{L} \mathrm{L}^{-1}\right)$
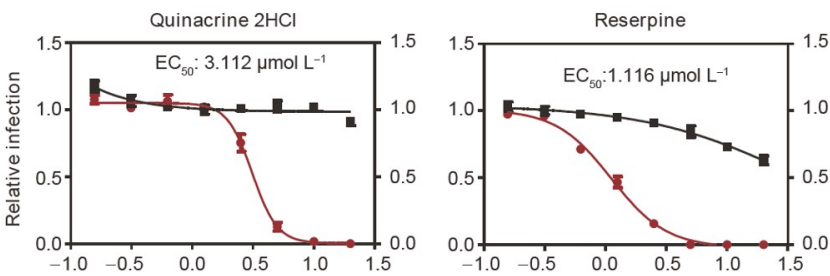

$\log \left(\right.$ Concentration $\left.\left(\mu \mathrm{mol} \mathrm{L} \mathrm{L}^{-1}\right)\right)$

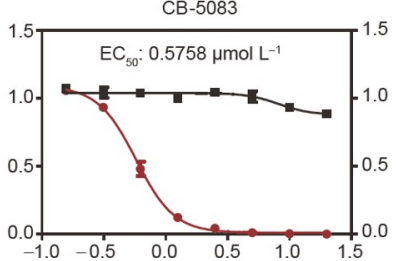

Log (Concentration $\left.\left(\mu \mathrm{mol} \mathrm{L}^{-1}\right)\right)$

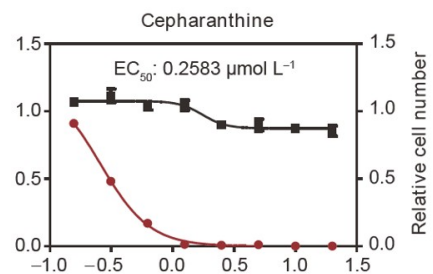

Log (Concentration $\left.\left(\mu \mathrm{mol} \mathrm{L}^{-1}\right)\right)$

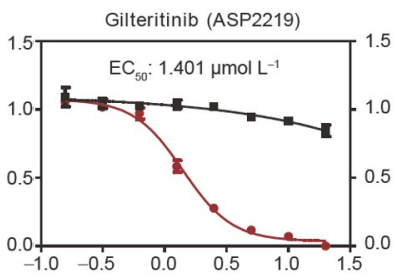

Log (Concentration $\left.\left(\mu \mathrm{mol} \mathrm{L}^{-1}\right)\right)$
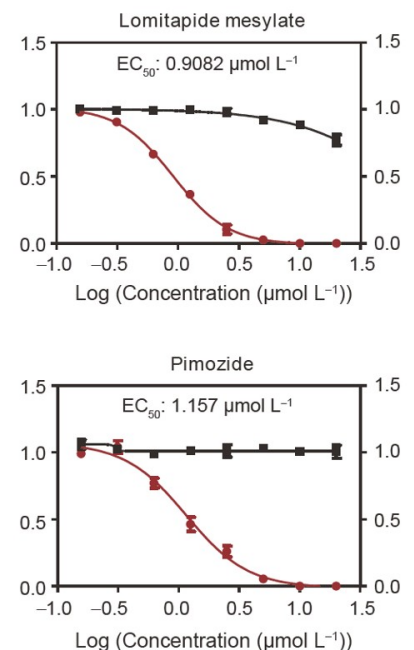

Log (Concentration ( $\left.\mu \mathrm{mol} \mathrm{L}^{-1}\right)$ )

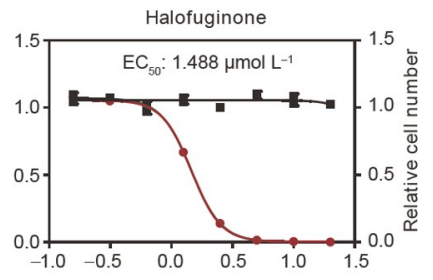

Log (Concentration $\left.\left(\mu \mathrm{mol} \mathrm{L} \mathrm{L}^{-1}\right)\right)$
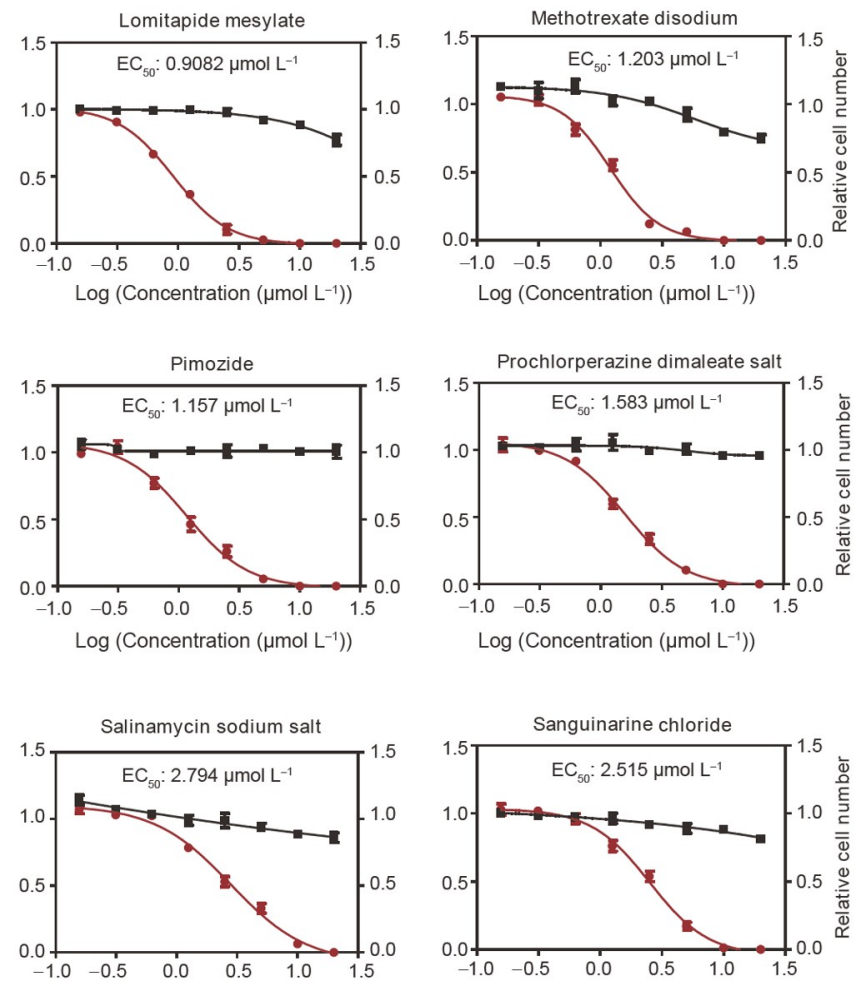

$\log ($ Concentration $(\mu \mathrm{mol} \mathrm{L}-1))$

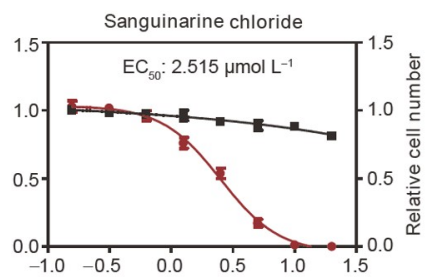

Log (Concentration $\left.\left(\mu \mathrm{mol} \mathrm{L} \mathrm{L}^{-1}\right)\right)$
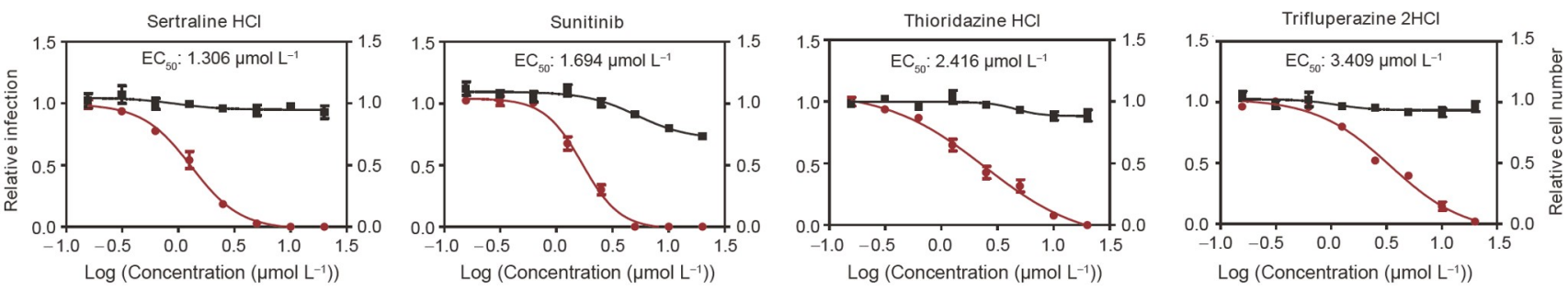

Log (Concentration $(\mu \mathrm{mol} \mathrm{L-1}))$

Figure 3 Dose-response relationship of selected anti-SARS-CoV-2 compounds in Vero E6 cells. Vero E6 cells were treated with eight 2-fold serial dilutions $\left(20-0.15625 \mu \mathrm{mol} \mathrm{L}^{-1}\right)$ of the indicated compounds and then infected with SARS-CoV-2 at an MOI of 0.1 . Then, $24 \mathrm{~h}$ postinfection, the cells were fixed and then SARS-CoV-2 NP and cell nuclei were visualized with immunofluorescence imaging. For each condition, the percentage of infection was calculated as the ratio of the number of infected cells stained for SARS-CoV-2 NP to the number of cells stained with DAPI. The ratios of SARS-CoV-2 infected cells (red), cell number (black), and cellular $\mathrm{EC}_{50}$ values are shown in the dose-response figures. Data are normalized to the average of DMSO-treated wells and represent mean \pm SEM for $n=3$ independent experiments. 

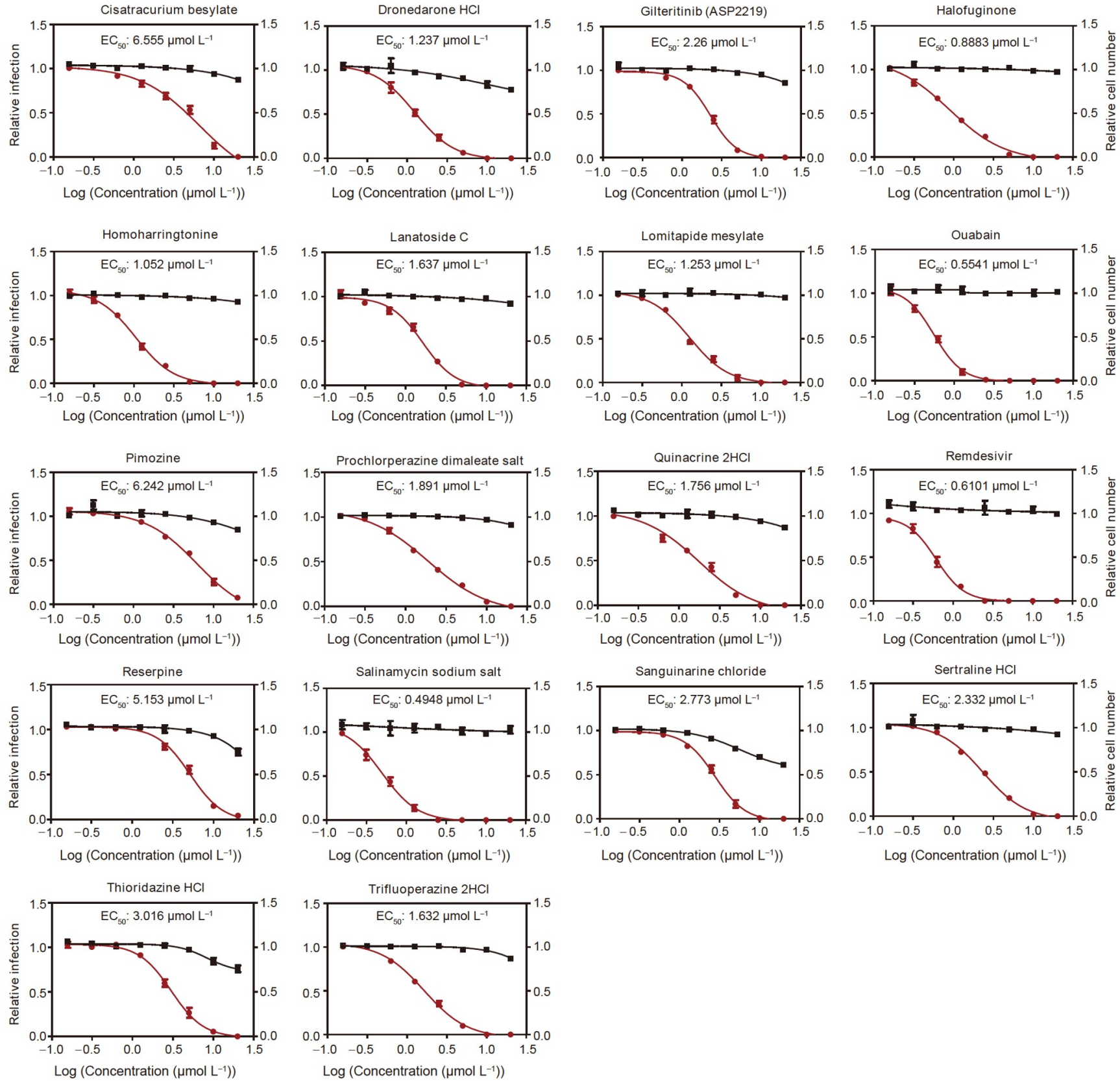

Figure 4 Dose-response relationship of selected compounds inhibiting SARS-CoV-2 in a human cerviral cancer cell line. HeLa-ACE2 (HeLa cells transduced with human angiotensin-converting enzyme 2) were treated with eight 2-fold serial dilutions $\left(20-0.15625 \mu \mathrm{mol} \mathrm{L}^{-1}\right)$ of the indicated compounds and then infected with SARS-CoV-2 (MOI=0.1). In the presence of the compounds, $24 \mathrm{~h}$ postinfection, the cells were fixed and analyzed by immunofluorescence imaging. For each condition, the percentage of infection was calculated as the ratio of the number of infected cells stained for nucleoprotein (NP) to the number of cells stained with DAPI. The ratios of SARS-CoV-2 infected cells (red), cell number (black), and cellular $\mathrm{EC}_{50}$ values are shown in the doseresponse figures. Data are normalized to the average of DMSO-treated wells and represent mean \pm SEM for $n=3$ independent experiments.

\section{Evaluation of the antiviral effect of the selected com- pounds in vivo}

The prophylactic efficacies of the selected compounds were determined in vivo using Syrian hamsters challenged with SARS-CoV-2. Syrian hamsters (six per group) were treated with different drugs via oral administration at suitable doses (Table 1) $1 \mathrm{~d}$ prior to the SARS-CoV-2 challenge, then administered daily for 10 consecutive days (Figure 6A). Re- mdesivir was used as a positive control. These doses had no significant effect on the weight, daily activity, and diet of the hamsters via safe dose evaluation. Compared with the vehicle-treated group, SARS-CoV-2-infected Syrian hamsters showed a body weight loss from 2 to $7 \mathrm{~d}$ postinfection (dpi), and the remdesivir-, gilteritinib-, salinomycin sodium salt-, sertraline $\mathrm{HCl}$, lomitapide mesylate-, cisatracurium besylate-, lanatoside $\mathrm{C}-$, and quinacrine $2 \mathrm{HCl}$-treated groups showed less body weight loss, and earlier weight regain, 

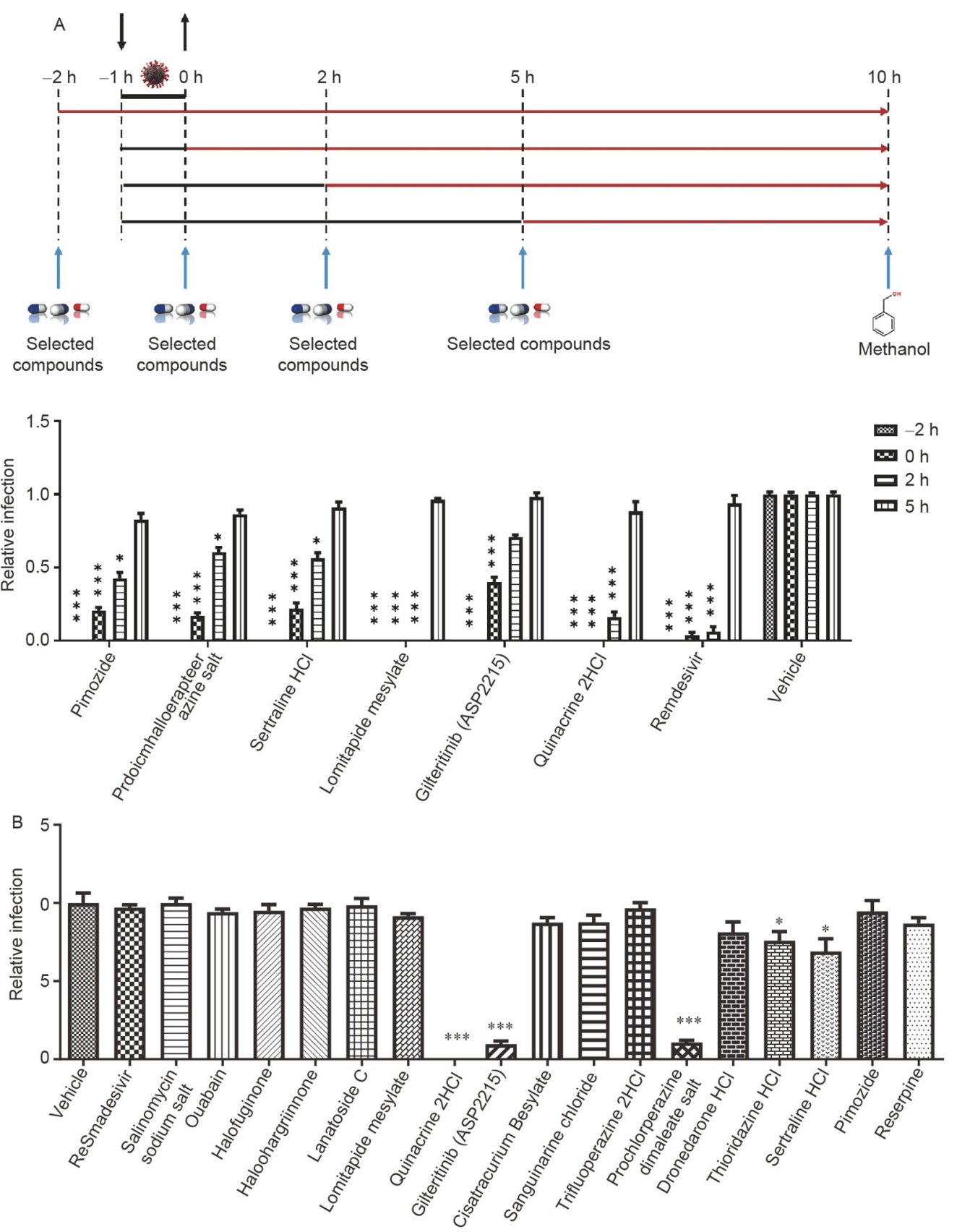

Figure 5 Effect of compounds on SARS-CoV-2 life cycle by time-of-drug addition assay and pseudoparticles entry assay. A, Time-of-drug addition assay. First, HeLa-ACE2 cells were incubated with SARS-CoV-2 for $1 \mathrm{~h}$ to synchronize the assay, and the culture medium was then removed. Cells were treated with the 18 selected compounds at a final concentration of $5 \mu \mathrm{mol} \mathrm{L} \mathrm{L}^{-1}$ at $-2,0,2$, and $5 \mathrm{~h}$ after the supernatants were removed. Then, the infection was qualified at $10 \mathrm{~h}$ postinoculation after fixation and staining for SARS-CoV-2 NP. Data were normalized to the mean of vehicle (DMSO)-treated wells for each indicated time point. Data are presented as mean \pm SEM of $n=3$ independent experiments. $\downarrow$, The time point of adding SARS-CoV-2. $\uparrow$, End of SARS-CoV-2 infection. B, Pseudoparticle entry assay. HeLa-ACE2 cells were pretreated with the compounds for $2 \mathrm{~h}$ at a final concentration of $5 \mu \mathrm{mol} \mathrm{L}^{-1}$ and then infected with SARS-CoV-2 pseudoparticles for $2 \mathrm{~h}$. Then the supernatant was removed. The infection was quantified $48 \mathrm{~h}$ postinfection. Data are presented as mean \pm SEM of $n=3$ independent experiments. One-way ANOVA followed by Dunnett $t$ post-test was performed as statistical analysis.

while the dronedarone $\mathrm{HCl}$-treated group showed decreased body weight loss, but slower weight regain (Figure 6B). Except for cisatracurium besylate-treated hamsters, the mean viral loads and the expression levels of $I L-6$ and $T N F-\alpha$ in the lung tissues of the above compound-treated animals were distinctly reduced compared with that of the vehicle-treated group when assayed at 4 dpi (Figure 6E).

Histopathological examination of the lungs indicated that the hamsters in the vehicle-treated group showed typical interstitial pneumonia, with infiltration of macrophages and lymphocytes into the alveolar interstitium, accumulation of macrophages in alveolar cavities, congestion of the 
A
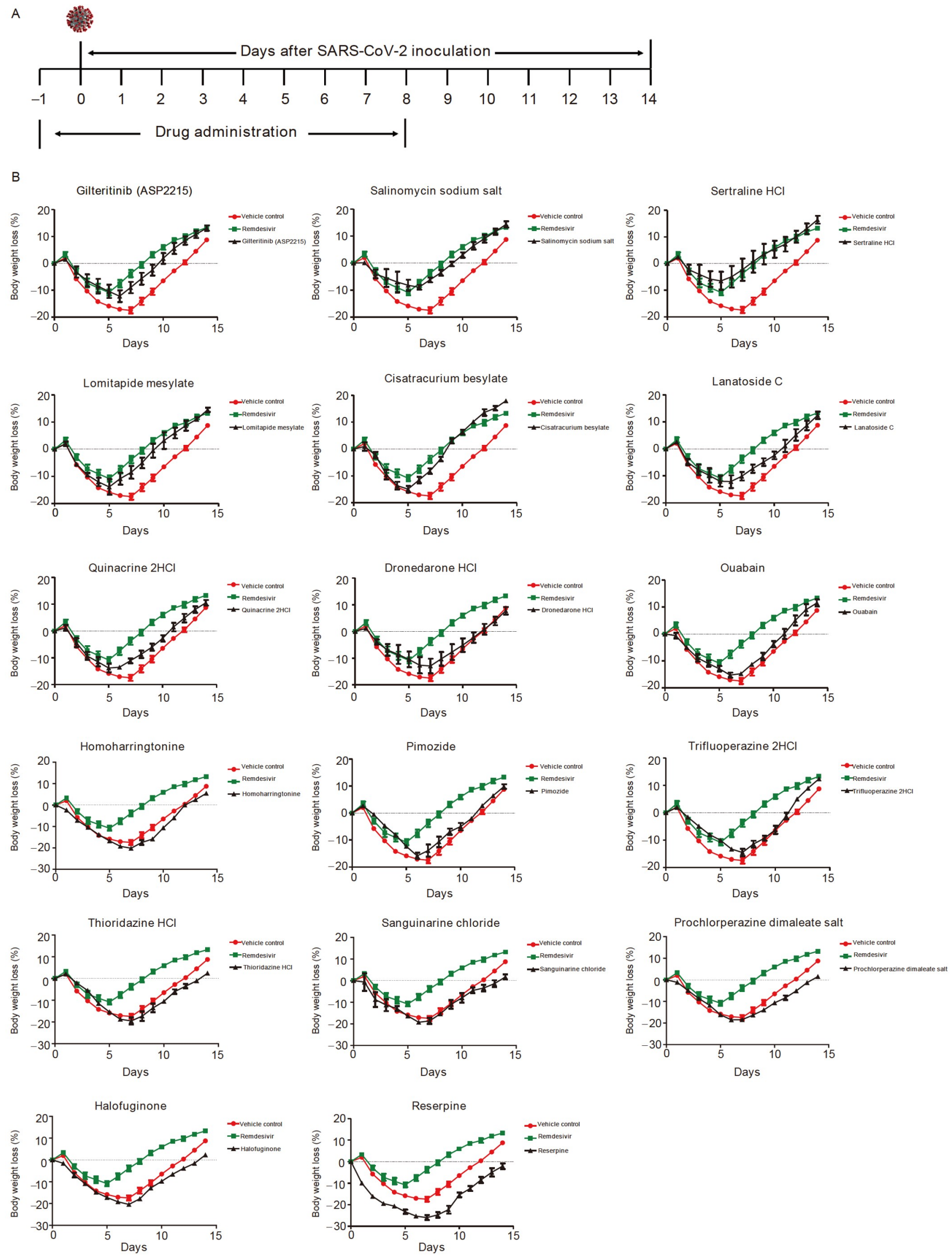

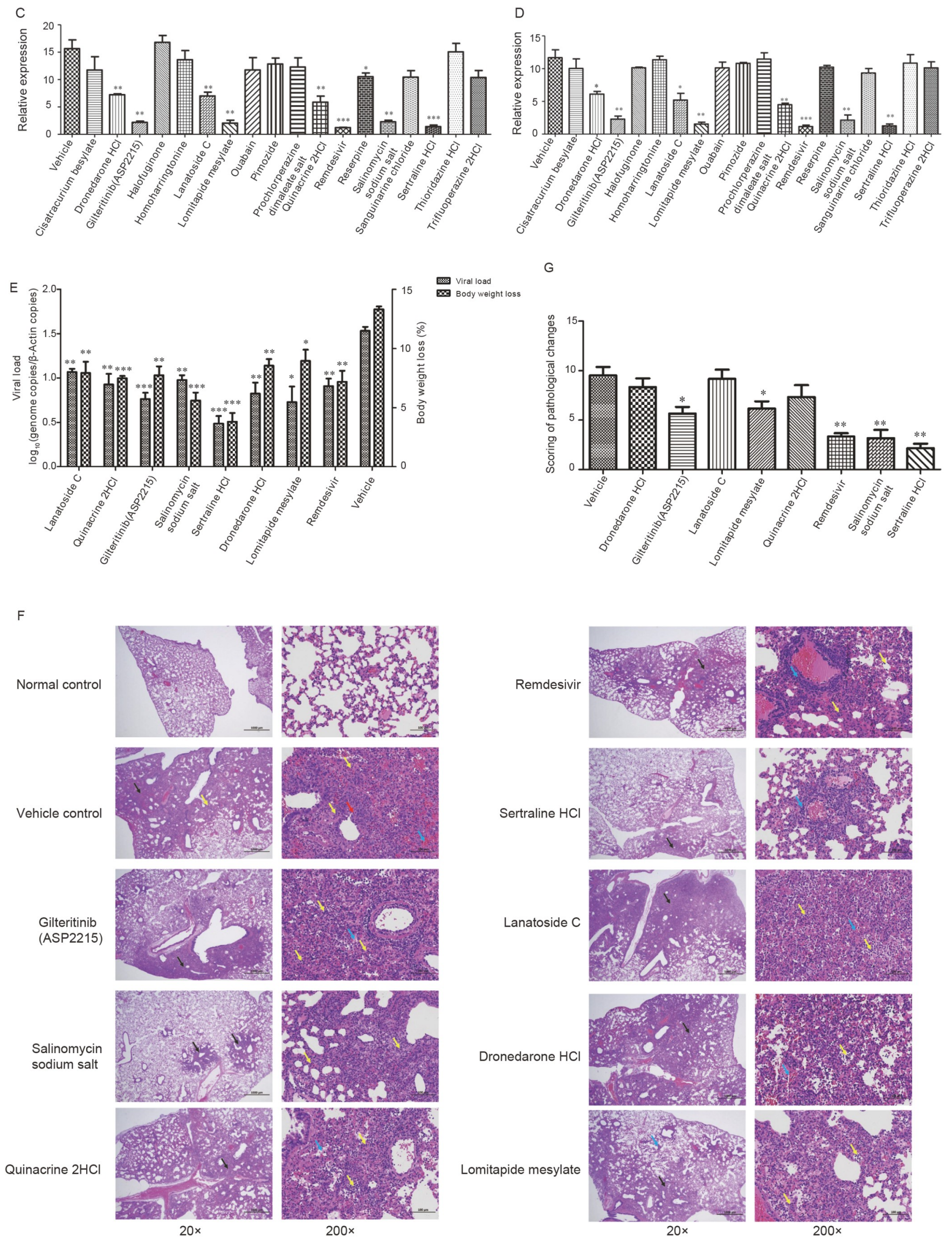

Biral load
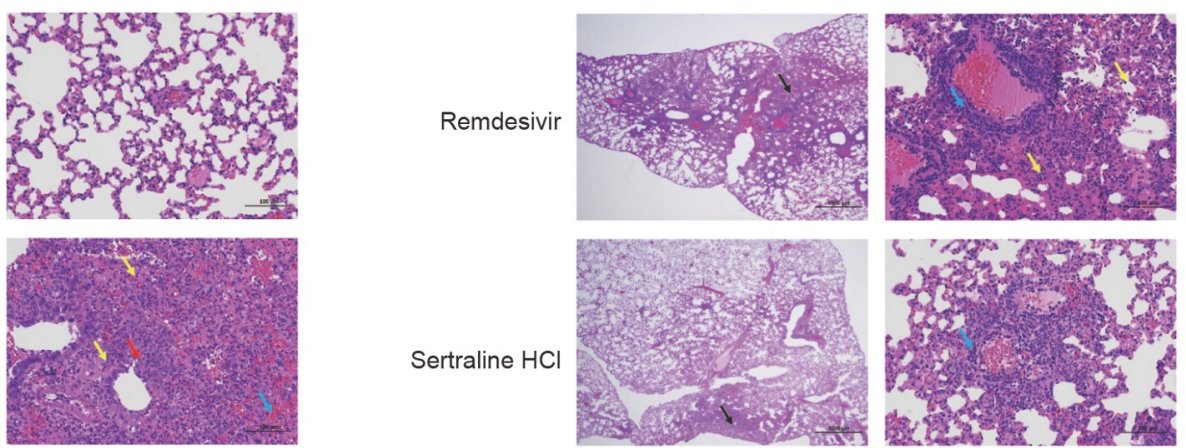

Sertraline $\mathrm{HC}$
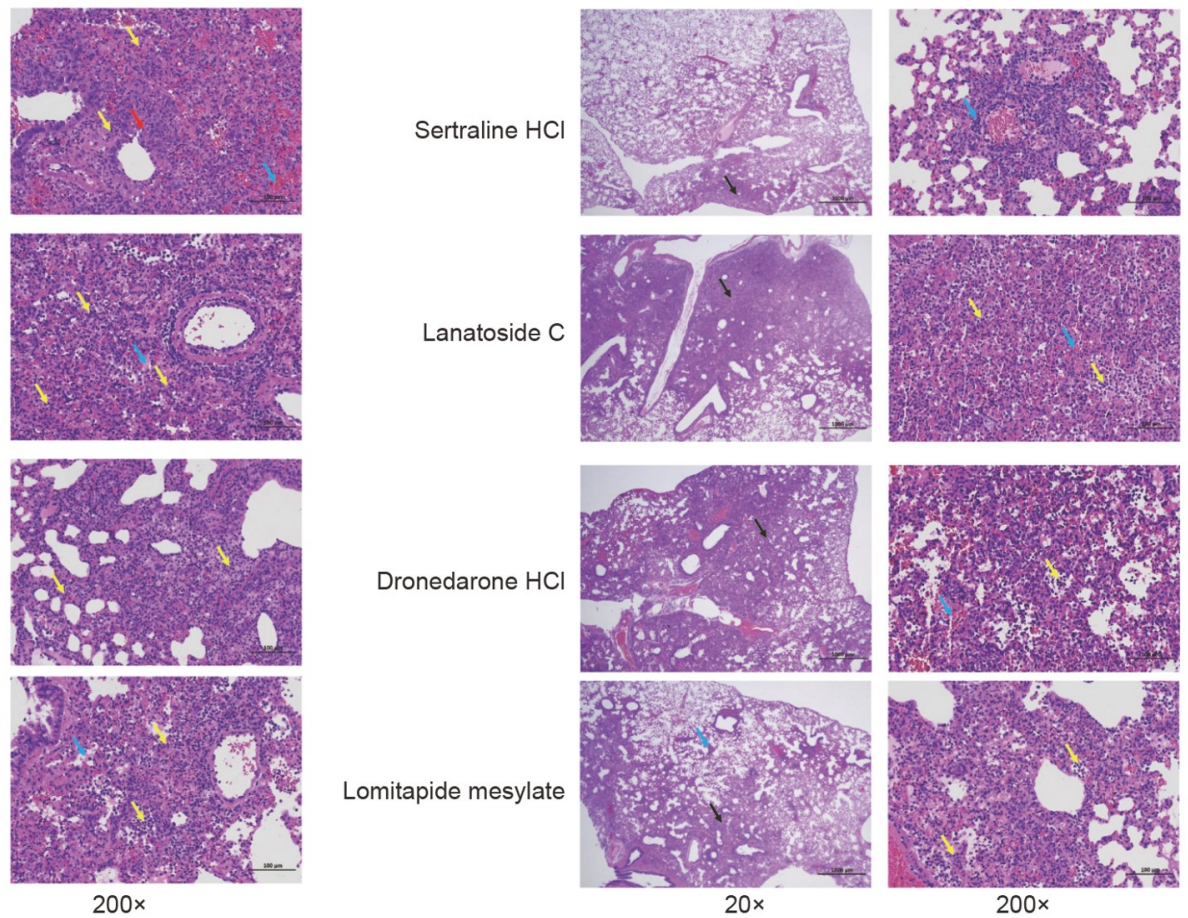

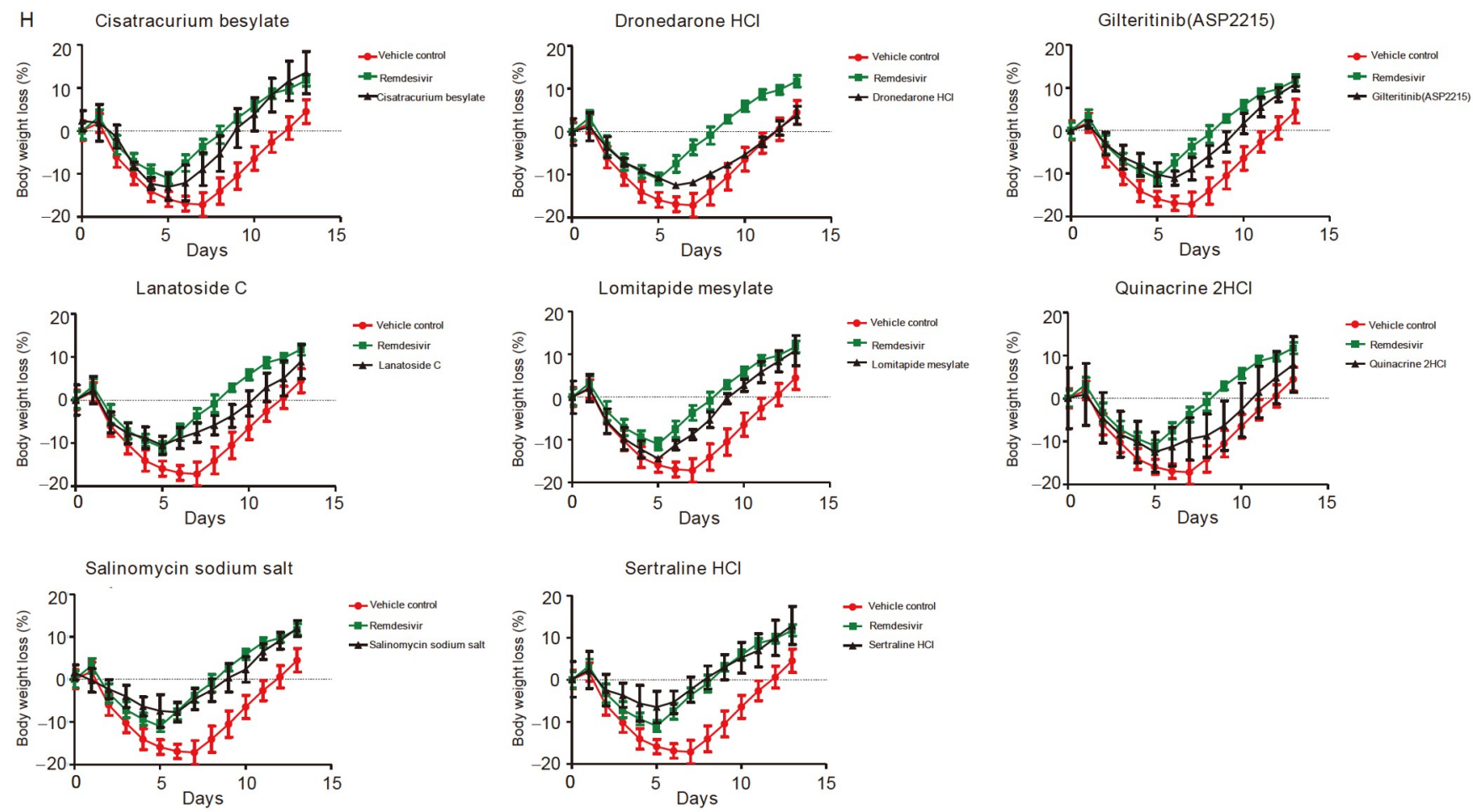

Figure 6 Antiviral efficacies of selected FDA-approved compounds against SARS-CoV-2 infection in hamsters. A, Schedule of drug treatments and SARSCoV-2 or SARS-CoV-2 spike D614G variant infection in hamsters. Six hamsters per group were incubated with $8 \times 10^{4} \mathrm{TCID}_{50}$ of SARS-CoV-2 in $80 \mu \mathrm{L}$ DMEM through the intranasal route on day 0. Additionally, each hamster of different groups was administered the indicated compounds or solvent buffer daily via oral administration for 10 consecutive days, starting at $1 \mathrm{~d}$ before infection. Three hamsters per group were monitored daily for body weights for $14 \mathrm{~d}$. The other three hamsters per group were sacrificed at $4 \mathrm{dpi}$. B, Weight changes are shown with standard errors of the means of three hamsters per group. Weight change is demonstrated as the percentage of the initial body weight of day 0 for all animals. C and D, Relative expression of $I L-6$ (C) and $T N F-\alpha$ (D) in the lower respiratory tract at 4 dpi were measured by RT-qPCR. E, Virus loads in the lower respiratory tract at 4 dpi were measured by determining the genome copies/ $\beta$-actin copies by RT-qPCR. Body weight loss of hamsters at 4 dpi. F, Histopathological changes in the lungs at 4 dpi. Affected areas of inflammation were identified histologically for each lung and compared between the groups. Low magnification $(20 \times)$ patches of alveolar inflammation (black arrows). High magnification $(200 \times)$ shows the hemorrhage and exudation (blue arrows), inflammatory cell infiltration (yellow arrows), and airway damage (red arrows). G, Pathological severity scores in infected hamsters. Lung tissue sections were scored based on pathological changes to evaluate comprehensive histological changes. Lung inflammation score taking into account (i) the severity of pulmonary inflammation; (ii) bronchitis; (iii) bronchial and alveolar necrosis; and (iv) hyperplasia of alveolar epithelial cells type II. H, Antiviral efficacies of selected FDA-approved compounds against SARSCoV-2 spike D614G variant infection in hamsters. Schedule of drug treatments and SARS-CoV-2 spike D614G variant infection in hamsters. Three hamsters per group were monitored daily for body weights for $14 \mathrm{~d}$. Error bars represent SEM for $n=3$ independent experiments. One-way ANOVA followed by Dunnett $t$ post-test was performed as statistical analysis.

capillaries, and stenosis or even disappearance of alveolar cavities (Figure 6F and $\mathrm{G}$ ). In contrast, remdesivir, gilteritinib, salinomycin sodium salt, sertraline $\mathrm{HCl}$, and lomitapide mesylate significantly alleviated the inflammation of lung tissues postvirus challenge. In particular, salinomycin sodium salt and sertraline $\mathrm{HCl}$ showed significant protective effects and relieved histopathological injuries.

The D614G mutation in the SARS-CoV-2 S-protein is associated with increased transmissibility, higher viral load, and younger aged patients (Plante et al., 2021; Volz et al., 2021). We determined the antiviral effect in vivo of the compounds on the D614G variant isolated from a SARSCoV-2-infected person in January 2021 (GenBank accession No. MZ664555). The weights of the D614G variant-infected hamsters administered with vehicle decreased from 2 to 7 dpi. Meanwhile, all of the eight compound-treated hamsters showed a body weight loss from 2 to 5 dpi. The remdesivir-, gilteritinib-, salinomycin sodium salt-, sertraline HCl-, lomitapide mesylate-, cisatracurium besylate-, lanatoside C-, and quinacrine 2HCl-treated groups showed less body weight loss compared with the vehicle-treated group (Figure $6 \mathrm{H})$. Interestingly, dronedarone $\mathrm{HCl}$ again reduced the body weight loss but did not shorten the period of weight recovery. Similar to the effect on the original strain, gilteritinib, salinomycin sodium salt, and sertraline $\mathrm{HCl}$ showed the most potent antiviral activity according to the time taken to regain the weight.

\section{Sustained treatment with a suboptimal concentration of compounds did not induce antiviral drug resistance}

Given the excellent antiviral properties of gilteritinib, salinomycin sodium salt, and sertraline $\mathrm{HCl}$ in vivo, we investigated the possibility of the generation of drug-resistant 
Table 1 Dosage of 18 different compounds in hamsters

\begin{tabular}{|c|c|c|c|c|c|}
\hline No. & Molecular name & Dosage $\left(\mathrm{mg} \mathrm{kg}^{-1}\right)$ & No. & Molecular name & Dosage $\left(\mathrm{mg} \mathrm{kg}^{-1}\right)$ \\
\hline 1 & Ouabain & 0.04 & 10 & Trifluoperazine $2 \mathrm{HCl}$ & 4 \\
\hline 2 & Lanatoside $\mathrm{C}$ & 3.3 & 11 & Pimozide & 6 \\
\hline 3 & Homoharringtonine & 2.1 & 12 & Prochlorperazine dimaleate salt & 5.7 \\
\hline 4 & Quinacrine $2 \mathrm{HCl}$ & 13 & 13 & Dronedarone $\mathrm{HCl}$ & 13.2 \\
\hline 5 & Gilteritinib & 6 & 14 & Sanguinarine chloride & 42 \\
\hline 6 & Salinomycin sodium salt & 6.6 & 15 & Lomitapide Mesylate & 0.5 \\
\hline 7 & Remdesivir & 6 & 16 & Cisatracurium Besylate & 1 \\
\hline 8 & Sertraline $\mathrm{HCl}$ & 26.4 & 17 & Reserpine & 6.6 \\
\hline 9 & Thioridazine hydrochloride & 5.6 & 18 & Halofuginone & 0.3 \\
\hline
\end{tabular}

viruses under suboptimal dose pressure. SARS-CoV-2 of the original strain was serially passaged 10 times in Vero E6 cells in the presence of half of the respective $\mathrm{EC}_{50}$, then the harvested virus at each passage was subjected to a drug sensitivity assay. The data showed that under the experimental conditions, none of the three compounds induced antiviral drug resistance (Table 2).

\section{DISCUSSION}

Despite the initiation of various medication research and clinical trials, effective antiviral drugs for COVID-19 treatment remain very limited. In this study, a high-throughput screening assay was used to identify anti-SARS-CoV-2 candidates from 2,580 FDA-approved small-molecule drugs, and 94 compounds were found to inhibit the infection of SARS-CoV-2 more than $90 \%$ at a concentration of $5 \mu \mathrm{mol} \mathrm{L}{ }^{-1}$ in Vero E6 cells. Although most of these hits overlapped with several recent drug repurposing screens, their antiviral effects in vivo have not been reported. In this screening, we first identified that perifosine (an inhibitor of Akt), CB-5083 (an inhibitor of a p97 AAA ATPase), sodium phytate (functions as a storage depot and a precursor for other inositol phosphates and pyrophosphates), and pimavanserin (an inverse agonist of serotonin 5-HT2A) can effectively inhibit infection of SARS-CoV-2. Their targets may serve as potential probes to identify cellular pathways that influence SARS-CoV-2 infection. The targets of these 94 compounds were classified into 14 categories, and the pathways that these targets are involved in were analyzed. The largest class was receptor tyrosine kinases, suggesting that phosphatase and kinase signaling have important roles in viral infection, which could serve as promising targets for antiviral drugs. Notably, EGFR is a pivotal target of a variety of viruses, the inhibitors of which harbor dual antiviral and antifibrotic activity in COVID-19 patients (Vagapova et al., 2021). However, the antiviral activity of some compounds may not be related to known host targets. For example, ba-
Table $2 \mathrm{EC}_{50}$ of three compounds to SARS-CoV-2 passage 0-10 under selection pressure

\begin{tabular}{cccc}
\hline \multirow{2}{*}{ Passage No. } & \multicolumn{3}{c}{$\mathrm{EC}_{50}\left(\mu \mathrm{mol} \mathrm{L}^{-1}\right)^{\mathrm{a})}$} \\
\cline { 2 - 4 } & Gilteritinib & Salinomycin sodium salt & Sertraline $\mathrm{HCl}$ \\
\hline 0 & 1.401 & 2.794 & 1.306 \\
1 & 1.416 & 2.831 & 1.247 \\
2 & 1.349 & 2.806 & 1.182 \\
3 & 1.501 & 2.619 & 1.191 \\
4 & 1.49 & 2.515 & 1.224 \\
5 & 1.331 & 2.989 & 1.485 \\
6 & 1.322 & 2.844 & 1.462 \\
7 & 1.47 & 2.787 & 1.219 \\
8 & 1.54 & 2.552 & 1.347 \\
9 & 1.398 & 2.762 & 1.263 \\
10 & 1.417 & 2.722 & 1.306 \\
\hline
\end{tabular}

a) $\mathrm{EC}_{50}$ values were measured after each passage.

zedoxifene is a selective estrogen receptor modulator, but our study showed that estradiol could not reverse or promote the antiviral activity of bazedoxifene (Figure S1 in Supporting Information). Masitinib, an inhibitor of Kit (c-Kit) and PDGFR $\alpha / \beta$, inhibited the $3 \mathrm{CL}^{\text {pro }}$ main proteases of coronaviruses and picornaviruses and was effective in reducing SARS-CoV-2 replication in mice (Drayman et al., 2021).

Similar to reports that drug screening is highly dependent on the chosen cell lines and infection conditions (Mirabelli et al., 2021), 17 of the 24 compounds were shown to inhibit SARS-CoV-2 infection in HeLa-ACE2 cells, including reported compounds with broad-spectrum antiviral activity, such as halofuginone, homoharringtonine, salinomycin sodium salt, ouabain, quinacrine $2 \mathrm{HCl}$, and three kinds of dopamine receptor inhibitors (including trifluoperazine $2 \mathrm{HCl}$, pimozide, and prochlorperazine dimaleate salt) (Chen et al., 2021; Ju et al., 2021; Nemerow and Cooper, 1984; Ochiai et al., 1991; Otręba et al., 2020). Dopamine receptor inhibitors have demonstrated broad-spectrum antiviral activity, including against influenza virus, herpes virus, 
hepatitis C virus, and SARS-CoV-2 (Berber and Doluca, 2021; Nemerow and Cooper, 1984; Ochiai et al., 1991; Otręba et al., 2020). These broad-spectrum antiviral repurposing candidates are of great significance for the treatment of various emerging viral infections.

As previously reported, many drugs demonstrated excellent anti-SARS-CoV-2 effects in cell infection systems, but clinical antiviral effects are far from expected (Geleris et al., 2020; Yu et al., 2021). Therefore, rigorous evaluation of the efficacy of candidates in animal models prior to clinical trials is necessary. The Syrian hamster model has been reported to be highly susceptible to SARS-CoV-2, with clear body weight losses (Gao et al., 2020b; Liu et al., 2020), making them readily available and valuable models for drug evaluation against SRAS-CoV-2 infection. Therefore, this model was adopted to investigate the anti-SARS-CoV-2 efficacy of the selected 17 hits together with remdesivir as a positive control. As far as we know, there are no previous reports on their efficacy against SARS-CoV-2 or other viruses in animals.

Prophylactic administration demonstrated that sertraline $\mathrm{HCl}$, salinomycin sodium salt, gilteritinib, and lomitapide mesylate reduced weight loss, lowered virus loads, and alleviated lung injury. In particular, sertraline $\mathrm{HCl}$, salinomycin sodium salt, and gilteritinib showed similar protective effects to remdesivir. Meanwhile, lanatoside $\mathrm{C}$ and quinacrine $2 \mathrm{HCl}$ slowed weight loss and inhibited the virus replication in lung tissues but failed to relieve pathological manifestations in the lung. Cisatracurium besylate effectively promoted weight regain of SARS-CoV-2 infected hamsters but did not reduce the viral load and inflammation in the lung when assayed at $4 \mathrm{dpi}$. Dronedarone decreased the magnitude of weight loss but did not reduce the duration of weight loss and that of weight recovery. The remaining nine hits neither reduced weight loss nor inhibited viral replication in hamster lung tissues. Ouabain and halofuginone did not show beneficial effects in vivo, despite their excellent antiviral activity in cell culture $\left(\mathrm{EC}_{50}<1 \mu \mathrm{mol} \mathrm{L}{ }^{-1}\right)$. Unexpectedly, reserpine treatment accelerated the weight loss of hamsters. These data highlight the importance of antiviral efficacy evaluation in animal models for the clinical application of repurposing drugs.

Sertraline is an antidepressant belonging to selective serotonin reuptake inhibitors. It has been reported to inhibit infection of the Ebola virus, Lassa virus, and arenavirus (Finch et al., 2021; Herring et al., 2021) via suppressing viral glycoprotein-mediated entry. Similarly, a more recent report indicated that sertraline prevented infection of Vero E6 cells with SARS-CoV-2 pseudoparticles and blocked SARS-CoV2 S-protein-mediated cell fusion (Carpinteiro et al., 2020; Xiao et al., 2020). In the present study, sertraline targets multiple processes of the SARS-CoV-2 life cycle, inhibiting not only viral spike-mediated entry but also viral replication
(Figure 4A). Another investigation showed that the combination of sertraline with oseltamivir prominently reduced lung inflammation and mortality induced by the influenza virus in mice, but sertraline had no effect on virus replication in vitro or in vivo (Sharma et al., 2013). Therefore, it is important to investigate whether sertraline exerts an immunomodulatory function to inhibit inflammation, an important mechanism that causes tissue damage of COVID-19.

Gilteritinib is a novel inhibitor of FLT3/AXL, clinically used for the treatment of FLT3-mutated acute myeloid leukemia (Ueno et al., 2016). It has been reported that gilteritinib inhibited SARS-CoV infection across multiple cell lines (Mirabelli et al., 2021). Gilteritinib inhibits the activity of eight kinases (Mori et al., 2017). SARS-CoV-2 infection changes the global phosphorylation landscape of host proteins dramatically, and pharmacologic inhibition of the p38, CK2, CDK, AXL, and PIKFYVE kinases has been reported to possess antiviral efficacy (Bouhaddou et al., 2020). It is remarkable that AXL is a candidate receptor for SARSCoV-2 that promotes the infection of pulmonary and bronchial epithelial cells (Wang et al., 2021). Thus, gilteritinib might be a potent repurposed drug for COVID-19. There is a report of successful therapy with gilteritinib in a patient with de novo FLT3-mutated acute myeloid leukemia and severe COVID-19 (Wilson et al., 2020).

Salinomycin, a polyether ionophore antibiotic isolated from Streptomyces albus, has been shown to kill cancer stem cells in different types of human cancers, most likely by interfering with ATP-binding cassette drug transporters and the Wnt/ $\beta$-catenin signaling pathway (Naujokat and Steinhart, 2012). It has been reported to have anti-SARS-CoV-2 activity in several in vitro studies (Ianevski et al., 2020; Ju et al., 2021; Yang et al., 2020). In the present study, the potency of the salinomycin sodium salt antiviral effect was verified with hamster models, which provided useful information for the future evaluation of the compound in clinical applications.

Dronedarone, an adrenergic receptor antagonist, and a potassium, sodium, and calcium channel inhibitor, inhibited the entry of filovirus (Gehring et al., 2014) and was reported to inhibit SARS-CoV-2 infection in rhesus monkey kidney LLC-MK2 cells (Xiao et al., 2020), which showed strong anti-SARS-CoV-2 efficacy in Vero E6 (Figure 2) and HeLaACE2 cells (Figure 3). Dronedarone may target the early stage of the SARS-CoV-2 life cycle but not S-mediated entry (Figure 5). Dronedarone significantly decreased the body weight loss, viral load, and inflammatory cytokines of the virus challenged hamsters; however, it did not affect the weight restoration overall.

Lomitapide mesylate is an effective microsomal triglyceride transfer protein inhibitor for the treatment of familial hypercholesterolemia. Lomitapide mesylate was first found to exhibit antiviral activity in a drug repurposing candidate 
screening for COVID-19 (Xing et al., 2021). Our results demonstrated that lomitapide mesylate could inhibit SARS$\mathrm{CoV}-2$ infection in vivo. It is possible that, as for many other viruses, the SARS-CoV-2 cell life is also regulated by the lipid metabolism of the host cells (Abu-Farha et al., 2020; Mirabelli et al., 2021).

Cisatracurium besylate, an AChR alpha-2 blocking agent, has been reported to be an inhibitor of SARS-CoV-2 RdRp in silico (Ahmad et al., 2020). In this study, its activity against SARS-CoV-2 was validated and confirmed to act at the postentry stage of the viral life cycle. In addition, Farsalinos et al. (2020) reported that SARS-CoV-2 might interact with nicotinic AChRs to dysregulate the nicotinic cholinergic system, and cisatracurium besylate may compete with SARS-CoV-2 to interact with nAChRs, with therapeutic value in COVID-19 patients. In the present animal study, cisatracurium besylate did not exert effects on hamster weight during the first $5 \mathrm{~d}$ postvirus infection, which is consistent with the lack of reduction of viral load and inflammation in the lung when assayed at $4 \mathrm{dpi}$. Then, it rapidly promoted hamster weight recovery, although its mechanism needs further investigation.

Lanatoside $\mathrm{C}$ is a cardiac glycoside with antiviral and antitumor activity, which has been reported to inhibit all four serotypes of dengue virus, flavivirus Kunjin, alphavirus Chikungunya, Sindbis virus, the human enterovirus 71, as well as SARS-CoV-2 (Cheung et al., 2014; Ginex et al., 2021).

Quinacrine is an effective phospholipase A2 inhibitor and an antimalarial drug, harboring antiviral activity to Ebola virus, Marburg virus, dengue virus type 2, Zika virus, and SARS-CoV-2 (Balasubramanian et al., 2017; Puhl et al., 2021). Raphael et al. reported that quinacrine can inhibit SARS-CoV-2 3CL ${ }^{\text {pro }}$ (Eberle et al., 2021). Our study revealed that quinacrine may act at multiple stages of SARS$\mathrm{CoV}-2$ replication, including S-mediated entry and postentry.

For the above drugs effectively inhibiting SARS-CoV-2 in hamsters, despite their maximum serum concentrations in the human body of the original indications recommended dose are lower compared to their $\mathrm{EC}_{50}$ against SARS-CoV-2 infection in cell culture obtained in this study, the doses equivalent to an estimated human doses administered in hamsters showed potent antiviral effect, hinting their potential therapeutic value to treat COVID-19.

Viral evolution is a common feature of RNA viruses and is the cause of prolonged epidemics, chronic viral infections, and antiviral drug resistance. The constant emergence of new SARS-CoV-2 variants challenges the development of timely, effective vaccines and drugs. The SARS-CoV-2 S-protein D614G mutation confers enhanced replication and transmissibility, and the G614 variant has replaced D614 as the dominant pandemic form worldwide. Remdesivir, sertraline $\mathrm{HCl}$, gilteritinib, salinomycin sodium salt, lomitapide me- sylate, dronedarone $\mathrm{HCl}$, cisatracurium besylate, lanatoside $\mathrm{C}$, and quinacrine $2 \mathrm{HCl}$ also exerted excellent antiviral activity against the D614G variant (Figure 6H). Moreover, for gilteritinib, salinomycin sodium salt, and sertraline $\mathrm{HCl}$ serial passage in the presence of low-concentration compounds failed to induce viral drug resistance. These data indicate that these candidates are promising for the treatment of continually emerging SARS-CoV-2 variants, which may be related to the fact that the host molecules are involved in the targets of these hits.

In summary, we discovered a list of clinically approved drugs capable of inhibiting SARS-CoV-2 in vitro in different cell lines, and we identified seven effective candidates in vivo using a hamster model. Our results show a high resistance barrier of gilteritinib, salinomycin sodium salt, and sertraline $\mathrm{HCl}$ via virus serial passages in cell culture, providing valuable information for their potential clinical application. Future research will be aimed at developing and evaluating therapeutic cocktails to optimize therapeutic options.

\section{MATERIALS AND METHODS}

\section{Cells and virus}

The African green monkey kidney cell line Vero E6 (Cell Bank of the Chinese Academy of Sciences, Shanghai, China, kindly provided by Dr. Rong Zhang, Fudan University), human embryonic kidney line 293T (ATCC CRL-3216), and HeLa (ATCC CCL-2) cells were maintained in Dulbecco's modified eagle medium (DMEM, Gibco, USA) supplemented with $10 \%$ fetal bovine serum (Sigma-Aldrich, USA), $1 \%$ penicillin/streptomycin (Thermo Fisher Scientific, USA), 1\% L-glutamine (Thermo Fisher Scientific), and 1\% non-essential amino acids (Thermo Fisher Scientific) at $37^{\circ} \mathrm{C}$ in a humidified atmosphere with $5 \% \mathrm{CO}_{2}$. SARS-CoV-2 strain (GenBank accession No. 622319) and D614G variant strain (GenBank accession No. MZ664555) were isolated from a laboratory-confirmed COVID-19 patient by passaging in Vero E6 cells (Peng et al., 2020). The virus working stocks were propagated and titrated in Vero E6 cells in the presence of TPCK-treated trypsin at a concentration of $2 \mu \mathrm{g} \mathrm{mL}^{-1}$, and the virus was stored at $-80^{\circ} \mathrm{C}$. All experiments involving infectious viruses were performed in the Biosafety Level 3 facility of Second Military Medical University.

\section{Compound library}

A Selleck library of FDA-approved drugs (L1300-Z349373), consisting of 2,580 compounds, was purchased from Selleck Chemicals (USA). All compounds were dissolved in dimethyl sulfoxide (DMSO) as a $10 \mathrm{mmol} \mathrm{L}^{-1}$ stock solution 
and stored at $-80^{\circ} \mathrm{C}$.

\section{Drug screening}

All compounds were diluted in culture media to a final concentration of $5 \mu \mathrm{mol} \mathrm{L}^{-1}$ during screening. A total of $1 \times 10^{4}$ Vero E6 cells were seeded in 96 -well plates. Then, $12 \mathrm{~h}$ later, the cells were treated with compounds at $37^{\circ} \mathrm{C}$ and $5 \% \mathrm{CO}_{2}$ prior to infection of SARS-CoV-2 at an MOI of 0.1 . All treatments were conducted in triplicate for each compound. DMSO vehicle controls were used on every plate. Then, $24 \mathrm{~h}$ postinfection, the cells were fixed with methyl alcohol for $30 \mathrm{~min}$ at $-20^{\circ} \mathrm{C}$. After blocking by $3 \%$ bovine serum albumin for $2 \mathrm{~h}$ at room temperature, the cells were incubated with rabbit polyclonal antibodies against the NP of SARS-CoV-2 (Sino Biological, Beijing, China) overnight at $4^{\circ} \mathrm{C}$. After 2 washes with PBS, the cells were incubated with Alexa Fluor 488-conjugated goat-anti-rabbit IgG (Thermo Fisher Scientific) for $1.5 \mathrm{~h}$ at room temperature. After 2 washes with PBS, the cells were added with DAPI (1:10,000 dilution, Sigma-Aldrich) and incubated for $15 \mathrm{~min}$ at room temperature. Images were acquired by using Cytation 5 (BioTek, USA). The numbers of infected cells and the total cells in each well were counted by Gen5 3.10. Then, the infection rate of each compound-treated group was calculated in Prism.

\section{Dose-response studies and $\mathrm{EC}_{50}$ calculation}

The antiviral activity of the selected compounds was further validated by dose-response studies, and the $\mathrm{EC}_{50}$ of each compound was calculated. In total, $1 \times 10^{4}$ Vero E6 cells or HeLa-ACE2 cells (generated as described below) were seeded in 96-well plates. Then, $12 \mathrm{~h}$ later, the cells were treated with eight 2-fold serial dilutions of compounds. The final concentration of the compounds ranged from $20 \mu \mathrm{mol} \mathrm{L}{ }^{-1}$ to $0.15625 \mu \mathrm{mol} \mathrm{L}^{-1}$. For control wells, a medium with vehicle DMSO was added to the cells. SARS-CoV-2 working stocks were added to the treated Vero E6 cells at an MOI of 0.1. At $24 \mathrm{~h}$ after the virus incubation, the SARS-CoV-2 infection was detected by immunofluorescence as described above. The $\mathrm{EC}_{50}$ of each compound was analyzed with Graph Pad 7 software. In addition, parallel plates without infection were performed to monitor the cytotoxicity of each compound. The cells were maintained at $37^{\circ} \mathrm{C}$, at $5 \% \mathrm{CO}_{2}$ for $48 \mathrm{~h}$ before performing a CCK-8 assay per the manufacturer's instructions (Beyotime, Shanghai, China). The $A_{450}$ was read by Synergy 2 (BioTek). The $\mathrm{CC}_{50}$ of each compound was calculated in Prism.

The human $A C E 2$ gene (Sino Biological) was PCR-amplified and inserted into the pCDH-CMV-Puro lentiviral vector (Addgene, USA). HeLa cells stably expressing human ACE2 (HeLa-ACE2) were constructed by the transduction of
HeLa cells with the lentivirion carrying the humanACE2 gene and were selected in the presence of puromycin. The expression of human $A C E 2$ was confirmed by western blotting using rabbit anti-human ACE2 monoclonal antibody (Sino Biological) as a detection antibody (Figure S2 in Supporting Information).

\section{Time-of-drug addition assay}

HeLa-ACE2 cells were seeded in 96-well plates at a density of $1 \times 10^{4}$ cells per well. Then, $12 \mathrm{~h}$ later, the cells were infected with SARS-CoV-2 (MOI=1.5). $1 \mathrm{~h}$ post-infection, the cell culture medium was removed, and the cells were washed twice with ice-cold PBS. Then, fresh medium was added to the wells. Indicated compounds (at a final concentration of $5 \mu \mathrm{mol} \mathrm{L}{ }^{-1}$ ) or DMSO (vehicle) were added at different time points, as illustrated in Figure 5A. Then, $10 \mathrm{~h}$ postinfection, the cells were fixed and subjected to an immunofluorescence assay using antibodies against SARS-CoV-2 NP.

\section{Pseudovirion evaluation of drug effects on cell entry}

Condon-optimized cDNA encoding the SARS-CoV-2 S glycoprotein (GenBank accession number: NC_045512) with a C-terminal 19 amino acid deletion was synthesized and cloned into the eukaryotic expression vector phCMV. SARS-CoV-2 S pseudoparticles were generated via cotransfection of HEK293T cells with HIV Gag/Pol, HIV rev, plenti-EGFP, and SARS-CoV-2 S expression plasmids using Lipofectamine 2000 reagent (Thermo Fisher Scientific) (Guan et al., 2012). Pseudovirions containing cell supernatants were harvested $2 \mathrm{~d}$ post-transfection and filtered using $0.45 \mu \mathrm{m}$ syringe filters, aliquoted, and stored at $-80^{\circ} \mathrm{C}$ until further use. For entry inhibition assays, HeLa-ACE2 cells $\left(1 \times 10^{4}\right.$ cells per well of a 96 well flat bottom plate $)$ were pretreated with the compounds at the indicated concentrations for $1 \mathrm{~h}$ prior to incubation with $20 \mu \mathrm{L}$ of SARS-CoV-2 $\mathrm{S}$ or control pseudoparticle supernatants. The green fluorescence protein-expressing cells were counted using the Cytation 5 cell imaging system (BioTek).

\section{Anti-SARS-CoV-2 activity in Syrian hamster model}

All procedures involving animals were reviewed and approved by the Institutional Committee for Animal Care and Biosafety of Second Military Medical University. All experiments complied with the relevant ethical regulations. The 6 week-old male Syrian golden hamsters (Beijing Vital River Laboratory Animal Technology Co., Ltd., China) were fed standard laboratory chow diet and water ad libitum. For the animal experiments, the hamsters were randomly distributed into 19 groups. Each group consisted of six hamsters. After anesthetization by isoflurane, hamsters in groups 1-18 
received an intranasal inoculation of $8 \times 10^{4} \mathrm{TCID}_{50}$ SARSCoV-2 in $80 \mu \mathrm{L}$ DMEM. The vehicle control group (19) was mock-treated with solvent buffer. Starting on the day prior to SARS-CoV-2 inoculation, hamsters in groups 1-18 received different compounds at appropriate doses (Table 1) via oral administration, once daily for 10 consecutive days. Three hamsters were monitored daily for body weights for $14 \mathrm{~d}$. The other three hamsters per group were sacrificed at $4 \mathrm{~d}$ postinfection, and their lungs were collected for virus loads evaluation, cytokine detection, and pathological examinations.

\section{Histopathological examination}

For histopathology, the right lung was removed, immersionfixed in $4 \%$ paraformaldehyde for $48 \mathrm{~h}$, embedded in paraffin, and cut into $4 \mu \mathrm{m}$ sections. Hematoxylin and eosin staining was performed after dewaxing in xylene and rehydration in decreasing ethanol concentrations. Images were obtained by $200 \times$ magnification using a digital microscope system (IX81; Olympus, Japan). The characteristics and severity of the pathologic lesions were scored using lungspecific inflammation parameters as previously reported (Francis et al., 2021). Three different scores were used that included the following parameters: (i) lung inflammation score including severity of interstitial pneumonia, bronchitis, epithelial necrosis of the bronchi and alveoli, and hyperplasia of type II-alveolar epithelial cells; (ii) immune cell infiltration score taking into account the presence of neutrophils, macrophages, and lymphocytes in the lungs as well as perivascular lymphocytic cuffing; and (iii) edema score, including alveolar edema and perivascular edema.

\section{RNA extraction and RT-qPCR}

To evaluate the viral loads and relative expression of $I L-6$ and $T N F-\alpha$, quantitative reverse transcription PCR (RTqPCR) was performed. Briefly, total RNA was extracted from hamster left lung tissues using TRizol Reagent (Thermo Fisher Scientific). The RNA concentrations and the A260/A280 ratio were assessed with a multiplate reader (Synergy 2; BioTek). RNA was converted into cDNA using a reverse transcription system (Promega, USA). The cDNA product was used for the following qPCR analysis directly, with TB Green Fast qPCR Mix (TaKaRa, Japan) and genespecific primers. Hamster $\beta$-actin expression was used for normalization. Additionally, expression plasmids of the SARS-CoV-2 $\mathrm{N}$ gene and hamster $\beta$-actin were used to make a standard curve. The following primers were used: SARSCoV-2 N gene, 5'-GGGGAACTTCTCCTGCTAGAAT-3' (forward) and 5'-CAGACATTTTGCTCTCAAGCTG-3' (reverse); hamster $\beta$-actin, 5'-AGCAGTCTGTTGGAGCAAGC-3' (forward) and 5'-TCTAGGGAATTGGGGTG-
GCT-3' (reverse); hamster IL-6, 5'-GAGACTGGGGATGTCTGTAGC-3' (forward) and 5'-GGATGGAAGTCTCTTGCGGAG-3' (reverse); hamster $T N F-\alpha, 5^{\prime}$-CCCAACCCTATCATCGGCTC-3' (forward) and 5'-TCCACTTGGTGGTTTGCTACA-3' (reverse).

\section{Induction of drug-resistance variants in cell culture}

Vero E6 cells were infected with SARS-CoV-2 at an MOI of 0.05 for $1 \mathrm{~h}$. Then the inoculum was removed, and Vero E6 cells were incubated with compounds at concentrations of half of their corresponding $\mathrm{EC}_{50}$ or in the absence of compounds to evaluate drug-induced resistance. The cell supernatants were harvested when a significant cytopathic effect was observed, which usually takes $3-4 \mathrm{~d}$ after viral infection. The titers of the harvested viruses were determined by plaque assays and were then used for the next passage and the $\mathrm{EC}_{50}$ assay of the corresponding compounds.

\section{Statistical analysis}

GraphPad Prism7 was used for statistical tests. Two-tailed Student's $t$-test was used to determine significant $P$-values for comparison of two groups, and one-way ANOVA followed by Tukey or Bonferroni posthoc tests were used for multiple comparisons. Differences were considered statistically significant when $P<0.05$. All data are presented as mean \pm SEM. $P$-values are indicated by $*, P<0.05$, ${ }^{*} P<0.01$ and $* * *, P<0.001$.

\section{Data availability statement}

The raw data supporting the conclusions of this article will be made available by the authors without undue reservation.

Compliance and ethics The author(s) declare that they have no conflict of interest.

Acknowledgements This work was supported by the National Natural Science Foundation of China (31570170) and the National Key Research and Development Program of China (2016YFC1200401).

\section{References}

Abu-Farha, M., Thanaraj, T.A., Qaddoumi, M.G., Hashem, A., Abubaker, J., and Al-Mulla, F. (2020). The role of lipid metabolism in COVID-19 virus infection and as a drug target. Int J Mol Sci 21, 3544.

Ahmad, J., Ikram, S., Ahmad, F., Rehman, I.U., and Mushtaq, M. (2020). SARS-CoV-2 RNA dependent RNA polymerase (RdRp) - a drug repurposing study. Heliyon 6, e04502.

Balasubramanian, A., Teramoto, T., Kulkarni, A.A., Bhattacharjee, A.K., and Padmanabhan, R. (2017). Antiviral activities of selected antimalarials against dengue virus type 2 and Zika virus. Antiviral Res 137, 141-150.

Berber, B., and Doluca, O. (2021). A comprehensive drug repurposing study for COVID19 treatment: novel putative dihydroorotate dehydrogenase inhibitors show association to serotonin-dopamine 
receptors. Brief Bioinform 22, 1023-1037.

Bouhaddou, M., Memon, D., Meyer, B., White, K.M., Rezelj, V.V., Correa Marrero, M., Polacco, B.J., Melnyk, J.E., Ulferts, S., Kaake, R.M., et al. (2020). The global phosphorylation landscape of SARS-CoV-2 infection. Cell 182, 685-712.e19.

Carpinteiro, A., Edwards, M.J., Hoffmann, M., Kochs, G., Gripp, B., Weigang, S., Adams, C., Carpinteiro, E., Gulbins, A., Keitsch, S., et al. (2020). Pharmacological inhibition of acid sphingomyelinase prevents uptake of SARS-CoV-2 by epithelial cells. Cell Rep Med 1, 100142.

Chen, Y., Lear, T.B., Evankovich, J.W., Larsen, M.B., Lin, B., Alfaras, I., Kennerdell, J.R., Salminen, L., Camarco, D.P., Lockwood, K.C., et al. (2021). A high-throughput screen for TMPRSS2 expression identifies FDA-approved compounds that can limit SARS-CoV-2 entry. Nat Commun 12, 3907.

Cheung, Y.Y., Chen, K.C., Chen, H., Seng, E.K., and Chu, J.J.H. (2014). Antiviral activity of lanatoside $\mathrm{C}$ against dengue virus infection. Antiviral Res 111, 93-99.

Dittmar, M., Lee, J.S., Whig, K., Segrist, E., Li, M., Kamalia, B., Castellana, L., Ayyanathan, K., Cardenas-Diaz, F.L., Morrisey, E.E., et al. (2021). Drug repurposing screens reveal cell-type-specific entry pathways and FDA-approved drugs active against SARS-CoV-2. Cell Rep 35, 108959.

Drayman, N., DeMarco, J.K., Jones, K.A., Azizi, S.A., Froggatt, H.M., Tan, K., Maltseva, N.I., Chen, S., Nicolaescu, V., Dvorkin, S., et al. (2021). Masitinib is a broad coronavirus 3CL inhibitor that blocks replication of SARS-CoV-2. Science 373, 931-936.

Eberle, R.J., Olivier, D.S., Amaral, M.S., Gering, I., Willbold, D., Arni, R. K., and Coronado, M.A. (2021). The repurposed drugs suramin and quinacrine cooperatively inhibit SARS-CoV-2 $3 \mathrm{CL}^{\text {pro }}$ in vitro. Viruses 13,873 .

Farsalinos, K., Eliopoulos, E., Leonidas, D.D., Papadopoulos, G.E., Tzartos, S., and Poulas, K. (2020). Nicotinic cholinergic system and COVID-19: in silico identification of an interaction between SARSCoV-2 and nicotinic receptors with potential therapeutic targeting implications. Int J Mol Sci 21, 5807.

Finch, C.L., Dyall, J., Xu, S., Nelson, E.A., Postnikova, E., Liang, J.Y., Zhou, H., DeWald, L.E., Thomas, C.J., Wang, A., et al. (2021). Formulation, stability, pharmacokinetic, and modeling studies for tests of synergistic combinations of orally available approved drugs against ebola virus in vivo. Microorganisms 9, 566.

Francis, M.E., Goncin, U., Kroeker, A., Swan, C., Ralph, R., Lu, Y., Etzioni, A.L., Falzarano, D., Gerdts, V., Machtaler, S., et al. (2021). SARS-CoV-2 infection in the syrian hamster model causes inflammation as well as type I interferon dysregulation in both respiratory and non-respiratory tissues including the heart and kidney. PLoS Pathog 17, e1009705.

Gao, K., Nguyen, D.D., Chen, J., Wang, R., and Wei, G.W. (2020a). Repositioning of 8565 existing drugs for COVID-19. J Phys Chem Lett 11, 5373-5382.

Gao, M., Yang, L., Chen, X., Deng, Y., Yang, S., Xu, H., Chen, Z., and Gao, X. (2020b). A study on infectivity of asymptomatic SARS-CoV-2 carriers. Respir Med 169, 106026.

Gehring, G., Rohrmann, K., Atenchong, N., Mittler, E., Becker, S., Dahlmann, F., Pöhlmann, S., Vondran, F.W.R., David, S., Manns, M.P., et al. (2014). The clinically approved drugs amiodarone, dronedarone and verapamil inhibit filovirus cell entry. J Antimicrob Chemother 69, 2123-2131.

Geleris, J., Sun, Y., Platt, J., Zucker, J., Baldwin, M., Hripcsak, G., Labella, A., Manson, D.K., Kubin, C., Barr, R.G., et al. (2020). Observational study of hydroxychloroquine in hospitalized patients with COVID-19. N Engl J Med 382, 2411-2418.

Ginex, T., Garaigorta, U., Ramírez, D., Castro, V., Nozal, V., Maestro, I., García-Cárceles, J., Campillo, N.E., Martinez, A., Gastaminza, P., et al. (2021). Host-directed FDA-approved drugs with antiviral activity against SARS-CoV-2 identified by hierarchical in silico/in vitro screening methods. Pharmaceuticals 14, 332.

Global report investigating novel coronavirus haplotypes. https://cov- lineages.org/global_report.html.

Guan, M., Wang, W., Liu, X., Tong, Y., Liu, Y., Ren, H., Zhu, S., Dubuisson, J., Baumert, T.F., Zhu, Y., et al. (2012). Three different functional microdomains in the hepatitis $\mathrm{C}$ virus hypervariable region 1 (HVR1) mediate entry and immune evasion. J Biol Chem 287, 3563135645.

Han, Y., Duan, X., Yang, L., Nilsson-Payant, B.E., Wang, P., Duan, F., Tang, X., Yaron, T.M., Zhang, T., Uhl, S., et al. (2021). Identification of SARS-CoV-2 inhibitors using lung and colonic organoids. Nature 589, 270-275.

Herring, S., Oda, J.M., Wagoner, J., Kirchmeier, D., O’Connor, A., Nelson, E.A., Huang, Q., Liang, Y., DeWald, L.E., Johansen, L.M., et al. (2021). Inhibition of arenaviruses by combinations of orally available approved drugs. Antimicrob Agents Chemother 65.

Ianevski, A., Yao, R., Fenstad, M.H., Biza, S., Zusinaite, E., Reisberg, T., Lysvand, H., Løseth, K., Landsem, V.M., Malmring, J.F., et al. (2020). Potential antiviral options against SARS-CoV-2 infection. Viruses 12, 642.

Ju, X., Zhu, Y., Wang, Y., Li, J., Zhang, J., Gong, M., Ren, W., Li, S., Zhong, J., Zhang, L., et al. (2021). A novel cell culture system modeling the SARS-CoV-2 life cycle. PLoS Pathog 17, e1009439.

Li, Q., Cui, C., Xu, F., Zhao, J., Li, N., Li, H., Wang, T., Zhang, H., Liu, N., Wei, Y., et al. (2021). Evaluation of the efficacy and safety of hydroxychloroquine in comparison with chloroquine in moderate and severe patients with COVID-19. Sci China Life Sci 64, 660-663.

Liu, Z., Chu, R., Gong, L., Su, B., and Wu, J. (2020). The assessment of transmission efficiency and latent infection period in asymptomatic carriers of SARS-CoV-2 infection. Int J Infect Dis 99, 325-327.

Mahase, E. (2021). COVID-19: molnupiravir reduces risk of hospital admission or death by $50 \%$ in patients at risk, MSD reports. BMJ 375 , $\mathrm{n} 2422$.

Mirabelli, C., Wotring, J.W., Zhang, C.J., McCarty, S.M., Fursmidt, R., Pretto, C.D., Qiao, Y., Zhang, Y., Frum, T., Kadambi, N.S., et al. (2021). Morphological cell profiling of SARS-CoV-2 infection identifies drug repurposing candidates for COVID-19. Proc Natl Acad Sci USA 118, e2105815118.

Mori, M., Kaneko, N., Ueno, Y., Yamada, M., Tanaka, R., Saito, R., Shimada, I., Mori, K., and Kuromitsu, S. (2017). Gilteritinib, a FLT3/ AXL inhibitor, shows antileukemic activity in mouse models of FLT3 mutated acute myeloid leukemia. Invest New Drugs 35, 556-565.

Naujokat, C., and Steinhart, R. (2012). Salinomycin as a drug for targeting human cancer stem cells. J Biomed Biotechnol 2012, 1-17.

Nemerow, G.R., and Cooper, N.R. (1984). Infection of B lymphocytes by a human herpesvirus, Epstein-Barr virus, is blocked by calmodulin antagonists. Proc Natl Acad Sci U S A 81, 4955-4959.

Ochiai, H., Kurokawa, M., and Niwayama, S. (1991). Influence of trifluoperazine on the late stage of influenza virus infection in MDCK cells. Antiviral Res 15, 149-160.

Otręba, M., Kośmider, L., and Rzepecka-Stojko, A. (2020). Antiviral activity of chlorpromazine, fluphenazine, perphenazine, prochlorperazine, and thioridazine towards RNA-viruses. A review. Eur J Pharmacol 887, 173553.

Pandey, A., Nikam, A.N., Shreya, A.B., Mutalik, S.P., Gopalan, D., Kulkarni, S., Padya, B.S., Fernandes, G., Mutalik, S., and Prassl, R. (2020). Potential therapeutic targets for combating SARS-CoV-2: drug repurposing, clinical trials and recent advancements. Life Sci 256, 117883.

Patten, J.J., Keiser, P.T., Gysi, D., Menichetti, G., Mori, H., Donahue, C.J., Gan, X., Do Valle, I., Geoghegan-Barek, K., Anantpadma, M. et al. (2021). Multidose evaluation of 6,710 drug repurposing library identifies potent SARS-CoV-2 infection inhibitors in vitro and in vivo. bioRxiv doi: 10.1101/2021.04.20.440626.

Peng, H.R., Li, C.Z., Tang, H.L., Xue, J.Y., Chen, Z.H., Liang, X.S., Zhu, Y.M., Xia, B.H., Zhu, Y.J., Wu, J.J. et al. (2020). Isolation and identification of two strains of severe acute respiratory syndrome coronavirus 2 from coronavirus disease 2019 patients in Shanghai (in Chinese). Acad J Sec Mil Med Univ 41, 365-370. 
Plante, J.A., Liu, Y., Liu, J., Xia, H., Johnson, B.A., Lokugamage, K.G., Zhang, X., Muruato, A.E., Zou, J., Fontes-Garfias, C.R., et al. (2021). Spike mutation d614g alters SARS-CoV-2 fitness. Nature 592, 116121

Puhl, A.C., Fritch, E.J., Lane, T.R., Tse, L.V., Yount, B.L., Sacramento, C. Q., Fintelman-Rodrigues, N., Tavella, T.A., Maranhão Costa, F.T., Weston, S., et al. (2021). Repurposing the Ebola and Marburg virus inhibitors tilorone, quinacrine, and pyronaridine: In vitro activity against SARS-CoV-2 and potential mechanisms. ACS Omega 6, 74547468.

Rakedzon, S., Neuberger, A., Domb, A.J., Petersiel, N., and Schwartz, E. (2021). From hydroxychloroquine to ivermectin: what are the anti-viral properties of anti-parasitic drugs to combat SARS-CoV-2? J Travel Med 28, taab005.

Riva, L., Yuan, S., Yin, X., Martin-Sancho, L., Matsunaga, N., Pache, L., Burgstaller-Muehlbacher, S., De Jesus, P.D., Teriete, P., Hull, M.V., et al. (2020). Discovery of SARS-CoV-2 antiviral drugs through largescale compound repurposing. Nature 586, 113-119.

Sharma, G., Champalal Sharma, D., Hwei Fen, L., Pathak, M., Bethur, N., Pendharkar, V., Peiris, M., and Altmeyer, R. (2013). Reduction of influenza virus-induced lung inflammation and mortality in animals treated with a phosophodisestrase-4 inhibitor and a selective serotonin reuptake inhibitor. Emerg Microbes Infect 2, 1-9.

Ueno, Y., Mori, M., Kamiyama, Y., Kaneko, N., Isshiki, E., and Takeuchi, M. (2016). Gilteritinib (ASP2215), a novel FLT3/AXL inhibitor: Preclinical evaluation in combination with azacitidine in acute myeloid leukemia. Blood 128, 2830.

Vagapova, E.R., Lebedev, T.D., and Prassolov, V.S. (2021). Viral fibrotic scoring and drug screen based on MAPK activity uncovers EGFR as a key regulator of COVID-19 fibrosis. Sci Rep 11, 11234.

Volz, E., Hill, V., McCrone, J.T., Price, A., Jorgensen, D., O'Toole, Á., Southgate, J., Johnson, R., Jackson, B., Nascimento, F.F., et al. (2021). Evaluating the effects of SARS-CoV-2 spike mutation D614G on transmissibility and pathogenicity. Cell 184, 64-75.e11.

Wang, M., Cao, R., Zhang, L., Yang, X., Liu, J., Xu, M., Shi, Z., Hu, Z.,
Zhong, W., and Xiao, G. (2020). Remdesivir and chloroquine effectively inhibit the recently emerged novel coronavirus (2019$\mathrm{nCoV})$ in vitro. Cell Res 30, 269-271.

Wang, S., Qiu, Z., Hou, Y., Deng, X., Xu, W., Zheng, T., Wu, P., Xie, S., Bian, W., Zhang, C., et al. (2021). AXL is a candidate receptor for SARS-CoV-2 that promotes infection of pulmonary and bronchial epithelial cells. Cell Res 31, 126-140.

Wilson, A.J., Troy-Barnes, E., Subhan, M., Clark, F., Gupta, R., Fielding, A.K., Kottaridis, P., Mansour, M.R., O'Nions, J., Payne, E., et al. (2020). Successful remission induction therapy with gilteritinib in a patient with de novo FLT3-mutated acute myeloid leukaemia and severe COVID-19. Br J Haematol 190, e189-e190.

Xiao, X., Wang, C., Chang, D., Wang, Y., Dong, X., Jiao, T., Zhao, Z., Ren, L., Dela Cruz, C.S., Sharma, L., et al. (2020). Identification of potent and safe antiviral therapeutic candidates against SARS-CoV-2. Front Immunol 11, 586572.

Xing, J., Paithankar, S., Liu, K., Uhl, K., Li, X., Ko, M., Kim, S., Haskins, J., and Chen, B. (2021). Published anti-SARS-CoV-2 in vitro hits share common mechanisms of action that synergize with antivirals. Brief Bioinform 22.

Yang, C.W., Peng, T.T., Hsu, H.Y., Lee, Y.Z., Wu, S.H., Lin, W.H., Ke, Y. Y., Hsu, T.A., Yeh, T.K., Huang, W.Z., et al. (2020). Repurposing old drugs as antiviral agents for coronaviruses. Biomed J 43, 368-374.

Yu, B., Li, C., Chen, P., Li, J., Jiang, H., and Wang, D.W. (2021). Beneficial effects exerted by hydroxychloroquine in treating COVID-19 patients via protecting multiple organs. Sci China Life Sci 64, 330-333.

Zhou, S., Hill, C.S., Sarkar, S., Tse, L.V., Woodburn, B.M.D., Schinazi, R. F., Sheahan, T.P., Baric, R.S., Heise, M.T., and Swanstrom, R. (2021). $\beta$-d-N4-hydroxycytidine inhibits SARS-CoV-2 through lethal mutagenesis but is also mutagenic to mammalian cells. J Infect Dis 224, 415-419.

Zhou, Y., Zhou, B., Pache, L., Chang, M., Khodabakhshi, A.H., Tanaseichuk, O., Benner, C., and Chanda, S.K. (2019). Metascape provides a biologist-oriented resource for the analysis of systems-level datasets. Nat Commun 10, 1523.

\section{SUPPORTING INFORMATION}

The supporting information is available online at https://doi.org/10.1007/s11427-021-2031-7. The supporting materials are published as submitted, without typesetting or editing. The responsibility for scientific accuracy and content remains entirely with the authors. 